\title{
O enxame de diques de anfibolito do Cráton São Francisco meridional
}

\author{
Alexandre de Oliveira Chaves ${ }^{1}$
}

\begin{abstract}
Resumo Em níveis crustais mesozonais do Cráton São Francisco meridional, diques máficos datados em 2,19 Ga se constituíram em resposta à contração para NW ocorrida durante a Orogenia Transamazônica. Neste evento, o magma toleítico se alojou, cristalizou e se metamorfisou sintectonicamente ao longo de zonas de cisalhamento transcorrente que se desenvolviam sob condições metamórficas de fácies anfibolito alto. Em função disto, estes diques, que compõem o enxame denominado Paraopeba, são constituídos por anfibolitos e guardam localmente em seu interior um metadiabásio com texturas ígneas parcialmente preservadas e bordas do tipo sheared margins, com nítida textura nematogranoblástica.
\end{abstract}

Palavras-chave: diques máficos, zonas de cisalhamento transcorrente, Transamazônico, anfibolito.

\begin{abstract}
The amphibolite dyke swarm of the southern São Francisco Craton. In mesozonal crustal levels of southern São Francisco Craton, mafic dykes, dated at $2.19 \mathrm{Ga}$, were formed in response to NW contraction occurred during the Transamazonian Orogeny. In such event, tholeiitic magma has syntectonically intruded, crystallized and metamorphosed along transcurrent shear zones that developed under high amphibolite facies conditions. Because of this, these dykes, which make up the Paraopeba dyke swarm, are made of amphibolite and keep, locally, a coarse metadiabase with partially preserved igneous textures in the inner part but an amphibolite in sheared margins, with a distinct nematogranoblastic texture.
\end{abstract}

Keywords: mafic dykes, transcurrent shear zones, Transamazonian, amphibolites.

INTRODUÇÃO Diversos pesquisadores (Escher et al. 1975, Wilson et al. 1985, Park \& Tarney, 1987, Cadman et al. 1990) têm observado que muitos enxames de diques máficos parecem estar aproximadamente paralelos a grandes zonas de cisalhamento em regime de transcorrência, estando os diques associados e afetados por estas zonas. Park \& Tarney (op.cit.) afirmam que diques do paleoproterozoico, posicionados em terrenos de médio a alto grau metamórfico da Escócia e Groenlândia, mostram margens cisalhadas em virtude da movimentação horizontal ao longo das zonas de cisalhamento transcorrente (ZCT) nas quais estão inseridos. Estas observações apontam para o fato que diques máficos podem ter sua gênese, portanto, ligada ao desenvolvimento de ZCT.

Em termos gerais, é possível entender as relações entre diques e regime de transcorrência conforme apresentado na figura 1. Em 1a, não existe componente de cisalhamento associado e, portanto, não é transcorrência. Em 1b, existe um significativo movimento destral acompanhado por extensão; assim, o movimento continuado após a solidificação do dique conduzirá ao aparecimento de margens cisalhadas no mesmo (1c). Na prática, nenhuma ZCT é perfeitamente retilínea, o que permitirá o desenvolvimento de zonas alternadas de extensão e compressão, conforme mostra a figura $1 \mathrm{~d}$. Portanto, os segmentos transtensionais que permitem a fácil intrusão de magma básico (geralmente pouco viscoso) podem subsequentemente tornar-se zonas de cisalhamento simples ou mesmo de transpressão, com o desenvolvimento de margens cisalhadas nos diques. [a]

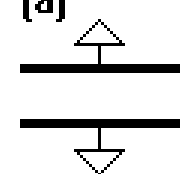

Dilatação

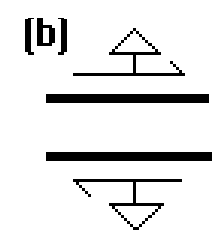

Transtensão [c]

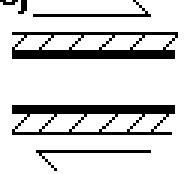

Cisalhament Simples

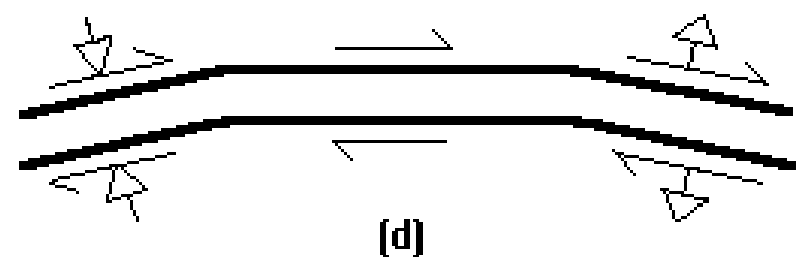

Transpressão
Transtensão
Figura 1 - (a) Stress extensional acompanhado por preenchimento de magma. (b) Transtensão: cisalhamento simples dextral acompanhado por extensão permite que o magma intruda. (c) Após a solidificação, o cisalhamento simples posterior produzirá margens cisalhadas nos diques. (d) Diques posicionados ao longo de zonas de cisalhamento não lineares permanentemente ativas que podem mostrar feições tanto transtensionais como transpressionais (Cadman et al. 1990). 
Segundo Cadman et al. (1990), existe um fator adicional de relevância a ser considerado: em diques que se estendem através de uma espessura apreciável da crosta continental, o tempo para a solidificação da parte mais profunda do dique deve ser muito mais longo do que aquele para as partes mais superiores do dique. Se movimentos transcorrentes ocorrem durante estes longos períodos, eles não serão registrados nas partes profundas (ainda líquidas) do dique, mas o dique por si mesmo ainda representará uma zona de fraqueza linear importante na crosta, que atuará como um locus para movimentos transcorrentes. Nas partes superiores solidificadas do dique, deve se desenvolver texturas de cisalhamento com grau metamórfico equivalente àquele das rochas encaixantes. Tais texturas são mais prováveis de se desenvolverem em níveis crustais intermediários (fácies anfibolito) enquanto a deformação em níveis ainda mais altos se dará por fraturamento rúptil. De toda maneira, as zonas de cisalhamento desenvolvidas atuam como canais importantes para a migração de fluidos que, por si só, auxiliam no desenvolvimento de texturas de cisalhamento nas margens dos diques.

Chaves \& Neves (2005) sistematizaram os enxames de diques máficos da porção sul do Cráton São Francisco, dentre os quais merece destaque o denominado Enxame Paraopeba, no qual os diques encontram-se anfibolitizados. Inserido no processo de geração de diques máficos em associação ao desenvolvimento de ZCT exposto por Cadman et al. (1990), o presente artigo tem como objetivo o detalhamento da caracterização petrográfica, litoestrutural, litogeoquímica, química mineral e geocronológica dos diques anfibolíticos do enxame Paraopeba. A integração destas informações serve aqui como subsídio para a compreensão da gênese do referido enxame no contexto da evolução paleoproterozoica do setor meridional do Cráton São Francisco.

GEOLOGIA REGIONAL A região investigada situa-se no domínio meridional do Cráton do São Francisco (Almeida 1977) onde se expõem terrenos granito-gnáissico-migmatíticos meso a neorqueanos, a sequência greenstone belt neoarqueana do Supergrupo Rio das Velhas, as supracrustais do Supergrupo Minas e a cobertura cratônica do Grupo Bambuí (Figs. 2 e 3).

Para os complexos granito-gnáissico-migmatíticos do sul do Cráton do São Francisco existe um acervo de datações $\mathrm{U}-\mathrm{Pb}$ que evidencia um longo período evolutivo, entre 3200 e 2600 Ma. Entretanto, os principais eventos de geração ou retrabalhamento desta crosta arqueana ocorreram no período de 2900 a $2700 \mathrm{Ma}$ (Machado \& Noce 1993).

O Supergrupo Rio das Velhas (Dorr II 1969) apresenta, em sua seção basal, filitos, xistos, formações ferríferas, dolomitos, quartzitos, metacherts, rochas máficas e metaultramáficas e, no topo, ocorrem quartzitos, conglomerados, xistos e filitos. O Quadrilátero Ferrífero (Fig. 2) é uma feição geológica de destaque inserida no sul do Cráton São Francisco e aparece parcialmente na porção SE da área investigada, onde itabiritos (minério de ferro que lhe confere o nome) e outras rochas metassedimentares do Supergrupo Minas afloram nas regiões das Serras do Curral e Moeda (Fig. 3). Estas serras margeiam parte do Supergrupo Rio das Velhas aflorante no interior do Quadrilátero Ferrífero. O Supergrupo Minas

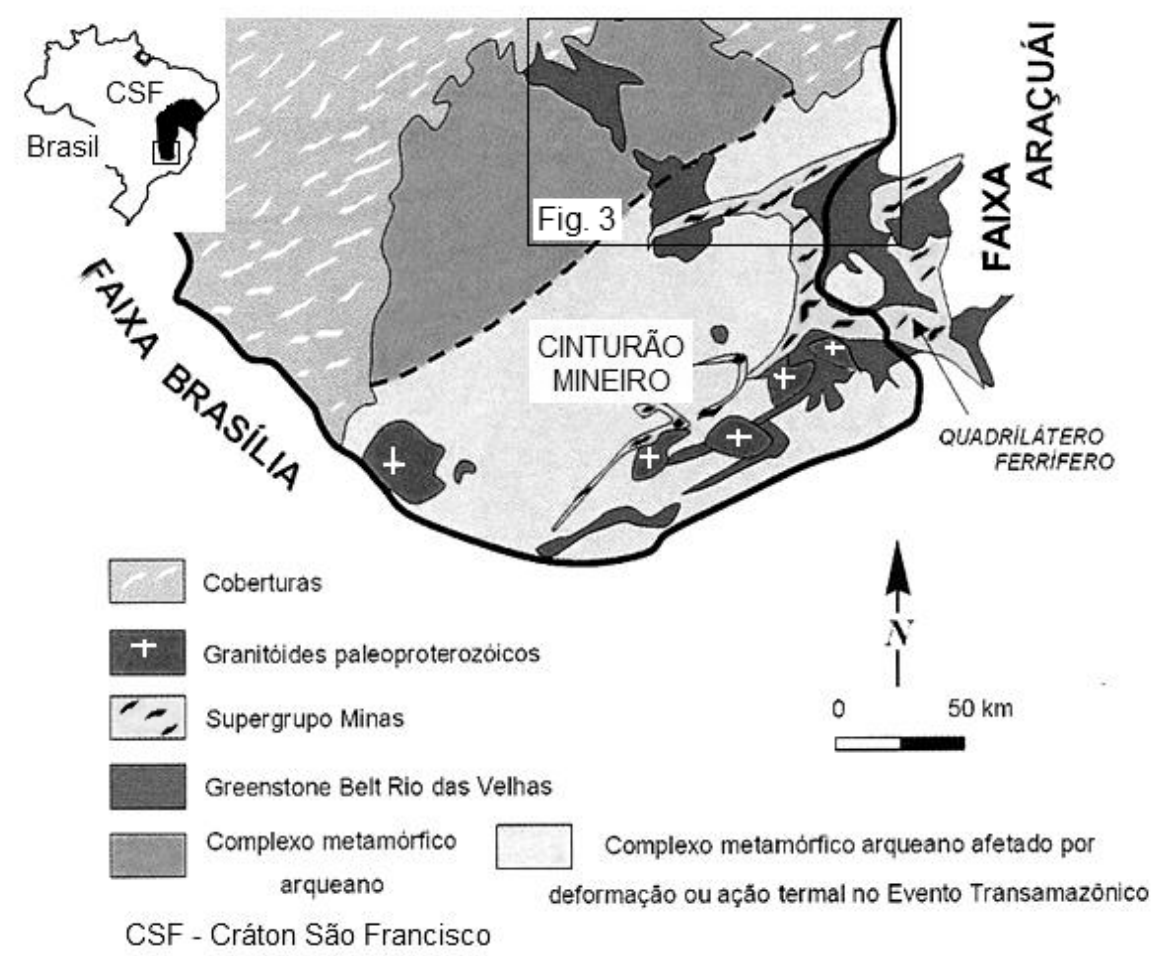

Figura 2 - Mapa geológico simplificado do extremo sul do Cráton São Francisco. 
(Dorr II 1969) é constituído predominantemente por sedimentos plataformais, empilhados em quatro grandes unidades que totalizam mais de $4.000 \mathrm{~m}$ de espessura. Engloba os sedimentos clásticos do Grupo Caraça, sedimentos químicos do Grupo Itabira (incluindo os itabiritos da Formação Cauê), unidades clásticas e químicas do Grupo Piracicaba e sedimentos do tipo flysh do Grupo Sabará. As rochas do Grupo Sabará evidenciam uma mudança nos sistemas deposicionais e nas áreas fonte de sedimentos em relação às demais unidades do Supergrupo Minas. A idade dos metassedimentos Caraça-Itabira foi estimada entre $2614 \mathrm{Ma}$ e $2420 \mathrm{Ma}$ e das rochas do Grupo Sabará entre 2125 Ma e $2030 \mathrm{Ma}$ (Babinski et al. 1995, Machado et al. 1996). O Grupo Itacolomi, composto por metarenitos e metaconglomerados aluviais, assenta-se discordantemente sobre todas as demais unidades do Supergrupo Minas.

Os grupos Sabará e Itacolomi são interpretados, respectivamente, como depósitos sin e pós-tectônicos em relação ao Evento Transamazônico, um evento compressivo de sentido aproximado SE para NW, responsável por boa parte da configuração do Quadrilátero Ferrífero (Alkmim \& Marshak 1998). A região de influência deste evento é denominada Cinturão Mineiro
(Teixeira et al. 2000), que engloba o Quadrilátero Ferrífero e os terrenos adjacentes a sudoeste, envolvendo o complexo metamórfico basal, as supracrustais do Supergrupo Rio das Velhas, o Supergrupo Minas, o Grupo Itacolomi, além de um substancial volume de granitoides arqueanos e paleoproterozoicos (Fig. 2). As suas extensões nordeste e sudoeste, fora do CSF, foram intensamente retrabalhadas durante o Evento Brasiliano no Neoproterozoico e constituem o substrato das faixas móveis Araçuaí e Brasília Sul, respectivamente.

O Grupo Bambuí (Fig. 3) é composto basicamente de rochas de composição metapelítica e carbonatada, de idade neoproterozoica (900-600 Ma) e, como um todo, possui espessura superior a $1.000 \mathrm{~m}$. Ele foi depositado em ambiente de mar raso do tipo epicontinental, em contexto geotectônico de uma bacia de antepaís (Thomaz Filho et al. 1998).

METODOLOGIA Reconhecimentos geológico/estruturais foram feitos na área investigada (Fig. 3), com coleta de amostras para estudos laboratoriais. A preparação das amostras para estudos petrográficos e geoquímicos, que inclui a laminação e também a cominuição do material, foi realizada nos laboratórios do Centro

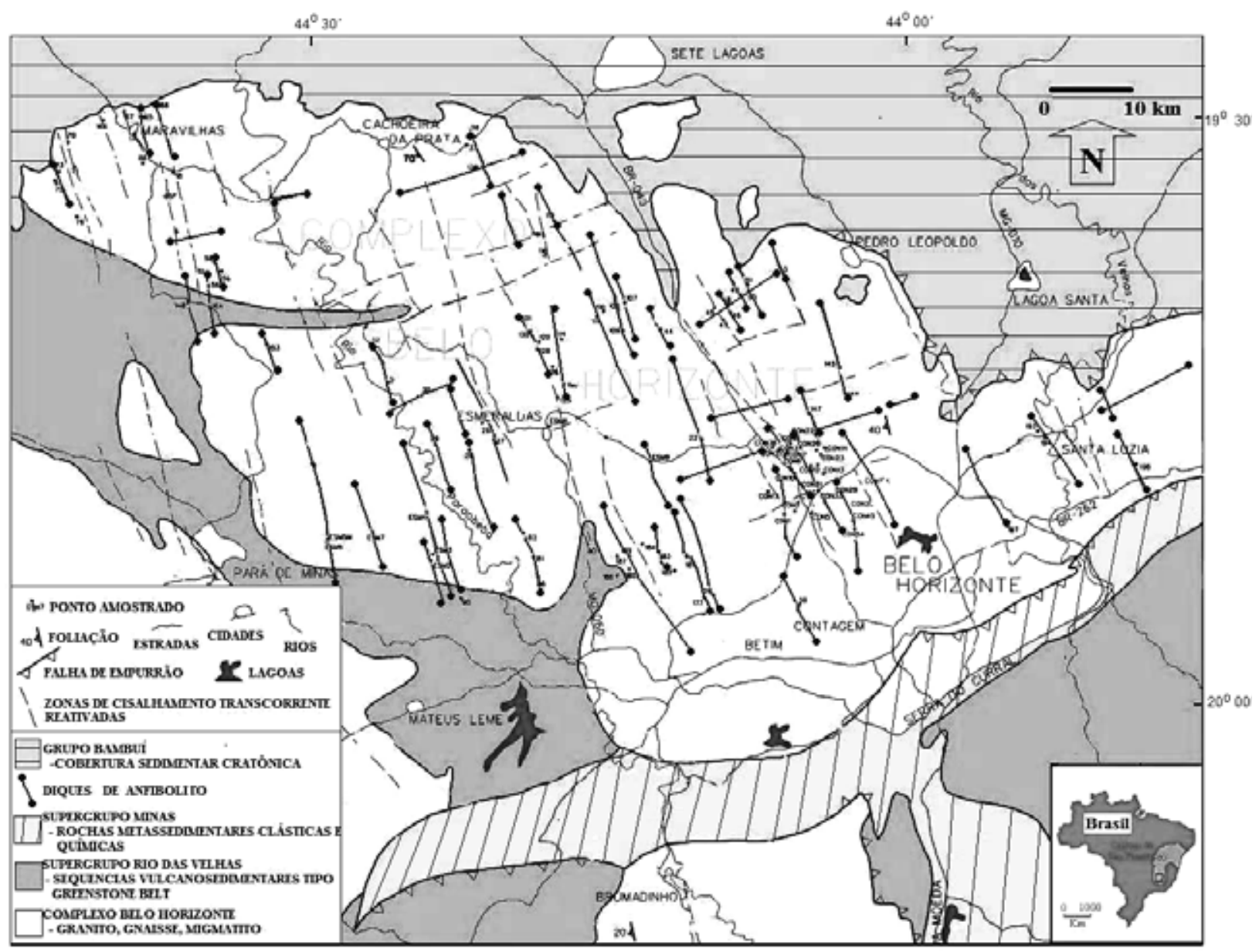

Figura 3 - Enxame Paraopeba de diques de anfibolito no contexto geológico da porção meridional do Cráton São Francisco. 
de Pesquisa Manoel Teixeira da Costa, do Instituto de Geociências da Universidade Federal de Minas Gerais (CPMTC-UFMG).

As investigações micropetrográficas foram feitas com o auxílio de um microscópio polarizador Leica DMR-XP de luz transmitida e refletida, com câmara fotográfica digital acoplada para a obtenção de fotomicrografias, instalado no CPMTC-UFMG. As microanálises das fases minerais em lâmina delgada polida foram realizadas através da microssonda eletrônica JEOL JXA-8900 RL WD/ED, instalada no Departamento de Física da UFMG, com o auxílio dos padrões analíticos adequados para cada mineral.

Quarenta amostras das porções centrais dos diques da área investigada foram cominuidas para fins de estudos geoquímicos. Os elementos maiores, traços e terras-raras foram analisados por fluorescência de raios-X (XRF) e espectroscopia de emissão por plasma (ICP) na Ecole des Mines de Saint-Etienne (França). Os óxidos de elementos maiores e os elementos traços $\mathrm{Rb}, \mathrm{Ba}$, $\mathrm{Sr}$, Hf e $\mathrm{Zr}$ foram determinados por XRF, enquanto que os demais traços e ETR foram analisados por ICP.

Para os estudos geocronológicos, com o auxílio do separador magnético Frantz e da lupa binocular (catação), foram obtidos, para uma amostra de um dos diques menos deformados, além da rocha total, três concentrados minerais previamente preparados com o auxílio de moinho de panela e separação granulométrica com peneira. Estes concentrados são a) minerais máficos/félsicos, isentos de minerais isolados por imã de mão, b) minerais máficos e c) minerais félsicos, seguindo a metodologia proposta por Pandey et al. (1997) para datação de diques.

A obtenção das razões ${ }^{87} \mathrm{Sr} /{ }^{86} \mathrm{Sr}$ e dos valores de $\mathrm{Rb}$ e $\mathrm{Sr}$ se deu no Centro de Pesquisas Geocronológicas da Universidade de São Paulo (CPGeo/USP) através da técnica de diluição isotópica. Este processo consiste na mistura da amostra com traçadores ("spikes") dos elementos que se deseja dosar, propiciando dados mais precisos. O procedimento químico para $\mathrm{Rb}-\mathrm{Sr}$ inicia-se com a pesagem da amostra, seguida de sua abertura, utilizando ácido nítrico e ácido fluorídrico na proporção 1:2. Após o ataque, a amostra é dissolvida em ácido clorídrico 2,62 N, sendo extraídas três alíquotas: estrôncio natural, estrôncio mais "spike" e rubídio mais "spike". Nas referidas alíquotas são adicionadas quantidades pré-calculadas de "spike" utilizando-se valores obtidos pela fluorescência de raios-x. Na sequência, as amostras são depositadas em colunas com resina de troca catiônica, das quais são coletados o Rb e o Sr utilizando ácido clorídrico 2,62 N. O material coletado, depois de seco, tem seu resíduo resultante analisado por espectrometria de massa.

Os valores de ${ }^{87} \mathrm{Sr} /{ }^{86} \mathrm{Sr}$ foram normalizados de acordo com a razão ${ }^{86} \mathrm{Sr} /{ }^{88} \mathrm{Sr}=0,1194$, sendo utilizadas nos cálculos as constantes propostas por Steiger \& Jager (1977), a saber: $\lambda_{\mathrm{Rb}}=1,42 \times 10^{-11}$ anos ${ }^{-1},{ }^{84} \mathrm{Sr} /{ }^{86} \mathrm{Sr}$ $=0,056584 \mathrm{e}^{85} \mathrm{Rb} /{ }^{87} \mathrm{Rb}=2,59265$. As demais razões utilizadas são: $\left({ }^{87} \mathrm{Sr} /{ }^{86} \mathrm{Sr}\right)_{\text {PRIMORDIAL }}$ [BABI] $=0,69898$; $\left({ }^{87} \mathrm{Rb} /{ }^{86} \mathrm{Sr}\right)_{\mathrm{DM} \text { atual }}=0,0494 ;\left({ }^{87} \mathrm{Rb} /{ }^{86} \mathrm{Sr}\right)_{\mathrm{UR} \text { atual }}=0,0816$;

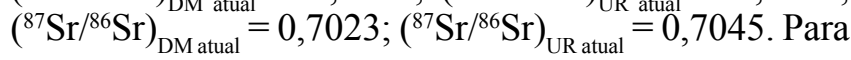

se obter a razão ${ }^{87} \mathrm{Rb} /{ }^{86} \mathrm{Sr}$ utilizou-se a seguinte equação: ${ }^{87} \mathrm{Rb} /{ }^{86} \mathrm{Sr}=2,8934 \mathrm{x}[\mathrm{Rb}(\mathrm{ppm}) / \mathrm{Sr}(\mathrm{ppm})]$. Os diagramas e cálculos isocrônicos foram obtidos com o auxílio do software ISOPLOT - versão 3.0 - de Ludwig (2003).

\section{GEOLOGIA, PETROGRAFIA E QUÍMICA MI- NERAL DOS DIQUES DE ANFIBOLITO Ao con-} trário dos diques dos demais enxames encontrados na área investigada e descritos por Chaves \& Neves (2005), os diques do enxame Paraopeba encontram-se metamorfisados. Segundo Chaves (1996), a rocha desses diques é um anfibolito ortoderivado com orientação preferencial de seus anfibólios prismáticos, conferindo foliação à rocha, principalmente nas porções marginais dos corpos, as quais podem ser caracterizadas como "sheared margins". Nas porções centrais dos diques, a rocha caracteriza-se macroscopicamente como um metadiabásio de textura gabroica, isento de orientação mineral preferencial. Blocos arredondados do material inalterado dos diques, com dimensões centimétricas a métricas, podem ser encontrados in situ e constituem a maior fonte de amostras frescas para estudo. Menos expressivamente, ocorrem também neste enxame alguns diabásios que foram originalmente porfiríticos e hoje mostram seus antigos fenocristais de plagioclásio deformacionalmente rotacionados. Tais fenocristais certamente são de cristalização anterior àquela dos minerais da antiga "matriz" ígnea que os circundava. Em alguns destes diabásios originalmente porfiríticos, é possível notar a assimetria de zonas de sombra ou feições de rompimento e deslocamento de subgrãos, formados pela recristalização parcial dos megacristais de plagioclásio, que rotacionaram e, portanto, servem também como indicadores cinemáticos sinistrais (Fig. 4).

Este enxame mostra diques cortando tanto gnaisses-migmatíticos e granitoides do Complexo Belo Horizonte, como também os litotipos do Supergrupo Rio das Velhas. Não são encontrados cortando litotipos do Supergrupo Minas nem aqueles do Grupo Bambuí. Os diques de anfibolito Paraopeba constituem discretos lineamentos ao longo de centenas de metros a cerca de duas dezenas de quilômetros e têm larguras que vão de $2 \mathrm{~m}$ a cerca de $80 \mathrm{~m}$, com média de $30 \mathrm{~m}$. Reconhecimentos estruturais na área investigada evidenciaram a presença de zonas de cisalhamento transcorrente (ZCT), de caráter dúctil, afetando rochas do Complexo Belo Horizonte e litotipos do Supergrupo Rio das Velhas. Estas ZCT mostram disposição vertical a subvertical e direções N10$-30 \mathrm{~W}$ (predominante) e N50-70E (subordinada). As ZCT predominantes, de movimentação sinistral, e as ZCT subordinadas, de movimentação dextral, ambas apontadas por slikensides e steps nos espelhos de falha, formam pares conjugados e simétricos em relação ao stress compressivo máximo horizontal $\left(\sigma_{1}\right)$. O mapeamento realizado revelou que os diques Paraopeba apresentam direções preferenciais N10-30W, que correspondem àquelas das ZCT predominantes, componentes mais desenvolvidas dos pares conjugados, como também N50-70E, direção das ZCT menos desenvolvidas (Chaves 1996). 


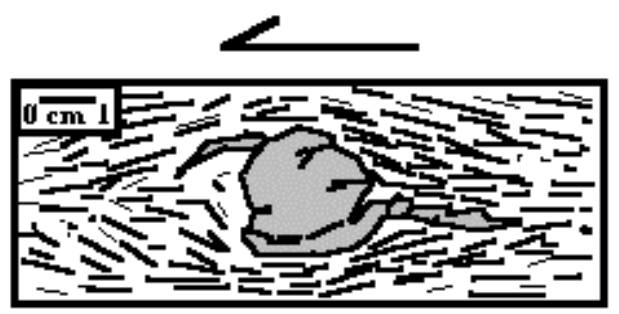

(A)

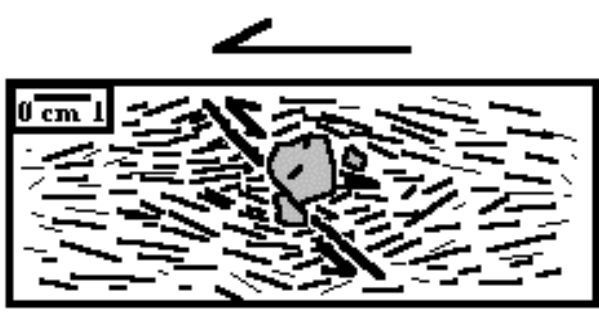

(B)

Figura 4 - Ilustração mostrando megacristais de plagioclásio deformacionalmente rotacionados, que servem como indicadores cinemáticos do movimento das ZCT sobre os diques de anfibolito. Em (A), é percebida a assimetria de zonas de sombra no plagioclásio e, em (B), o plagioclásio foi seccionado e o subgrão deslocado. Em ambos os casos, o movimento foi sinistral.

Em toda a extensão da área investigada, a maior parte das zonas de cisalhamento transcorrente transamazônicas foi reativada no Neoproterozoico como falhas rúpteis (Fig. 2). Desta forma, o material que aparece nestas falhas, quartzo-sericítico, consiste em cataclasitos. $\mathrm{Na}$ topografia do terreno, estes cataclasitos se destacam como cristas finas e contínuas que, em imagens de satélite, se assemelham às feições dos diques (Chaves 1996).

Cerca de 60 lâminas delgadas de anfibolitos foram investigadas. Estas rochas, que em afloramento exibem bordas foliadas e parte central maciça, mostram invariavelmente, em lâmina delgada, textura nematogranoblástica em amostras da borda (Fig. 5) e granoblástica em amostras do centro (Fig. 6) de praticamente todos os corpos. Em ambos os casos, conforme será visto adiante, além da recristalização evidente, a mineralogia ígnea original foi substituída pela metamórfica. Análises por microsonda eletrônica (Tab. 1) servem de suporte à investigação destas transformações mineralógicas e composições de cada mineral.

Plagioclásio Perfazendo cerca de $30-40 \%$ do volume da rocha, ocorre na forma de um aglomerado de cristais poligonais, normalmente exibindo extinção ondulante. Em alguns cristais, as maclas polissintéticas aparecem algo deformadas e descontínuas. As análises por microssonda eletrônica permitiram obter as composições em termos de (An,Ab) e as fórmulas cristaloquímicas a seguir indicadas:

\section{amostra 58 (três cristais):}

a) $\left(\begin{array}{llll}\left.\mathrm{Ab}_{51} \mathrm{An}_{49}\right) & \left(\mathrm{Na}_{0.51}\right. & \mathrm{Ca}_{0.49}\end{array}\right)\left[\begin{array}{lll}\mathrm{Al}_{1.47} & \mathrm{Si}_{2.53} & \mathrm{O}_{8}\end{array}\right]$ andesina/labradorita andesina

b) $\left(\mathrm{Ab}_{60} \mathrm{An}_{40}\right)\left(\mathrm{Na}_{0.60} \mathrm{Ca}_{0.36} \mathrm{Mn}{ }_{0.04}\right)\left[\mathrm{Al}_{1.38} \mathrm{Si}_{2.62} \mathrm{O}_{8}\right]$ andesina

c) $\left(\begin{array}{lllll}\mathrm{Ab}_{69} & \mathrm{An}_{31} & \left(\mathrm{Na}_{0.69}\right. & \mathrm{Ca}_{0.31}\end{array}\right)\left[\begin{array}{llll}\mathrm{Al}_{1.31} & \mathrm{Si}_{2.69} & \mathrm{O}_{8}\end{array}\right]-$

amostra 27 (dois cristais): andesina

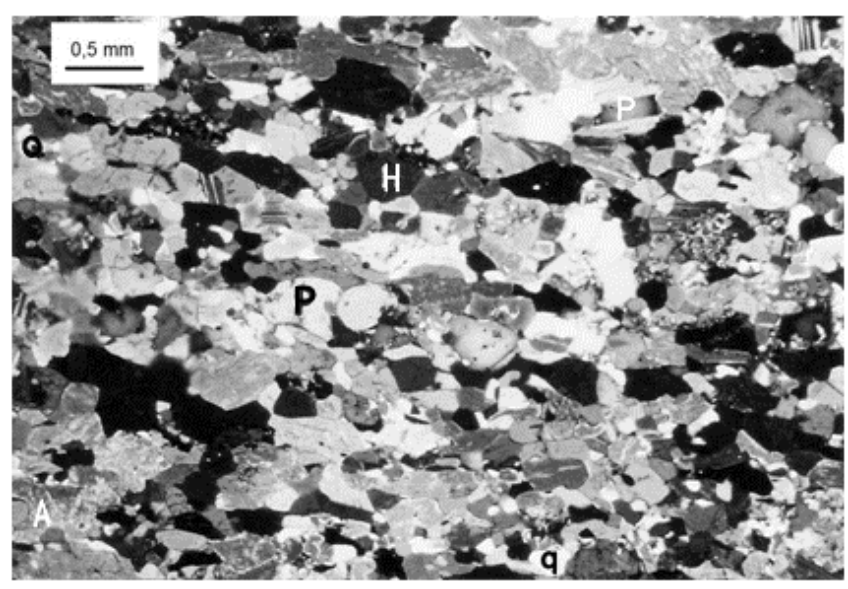

Figura 5 - Textura nematogranoblástica de uma amostra da porção marginal de um dique de anfibolito, sob nicóis cruzados. $P=$ plagioclásio, $H=$ hornblenda, $A=$ augita, $q=$ quartzo.

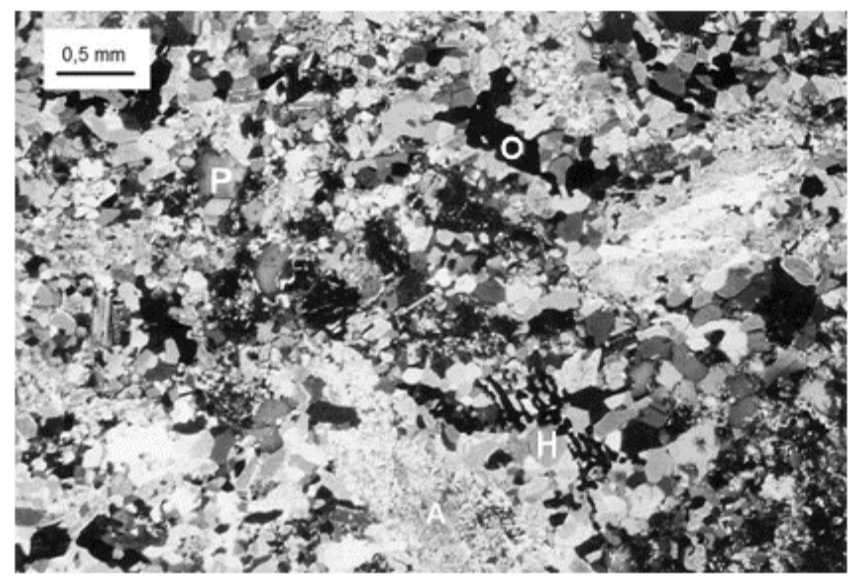

Figura 6 - Textura granoblástica de uma amostra da porção central de um dique de anfibolito, sob nicóis cruzados. $P=$ plagioclásio, $H=$ hornblenda, $A=$ augita, $O=$ opacos (ilmenita). 


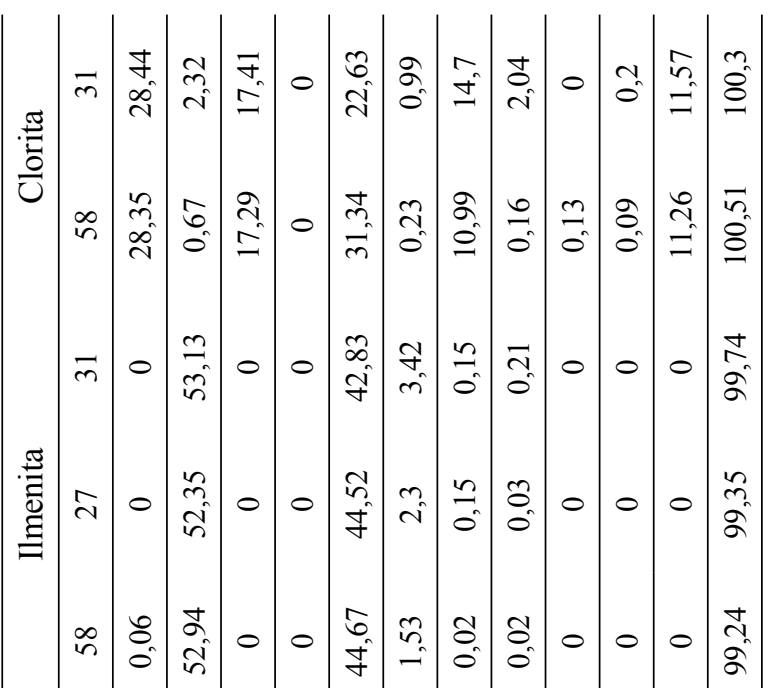

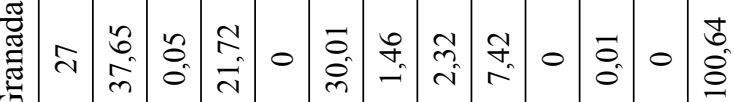

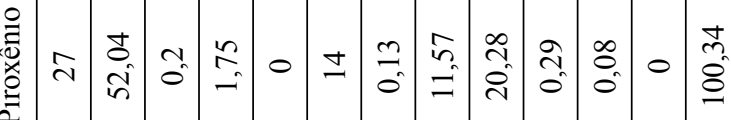

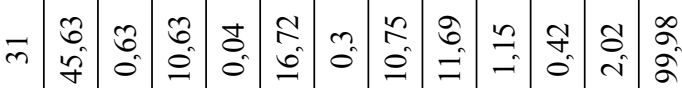

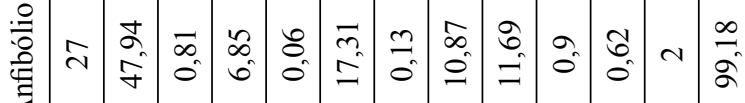

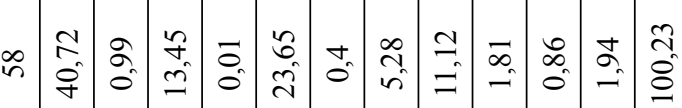

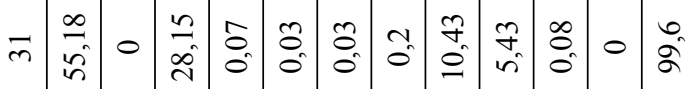

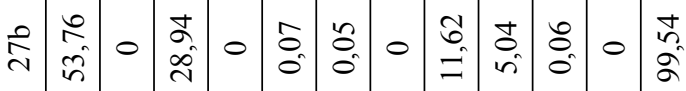

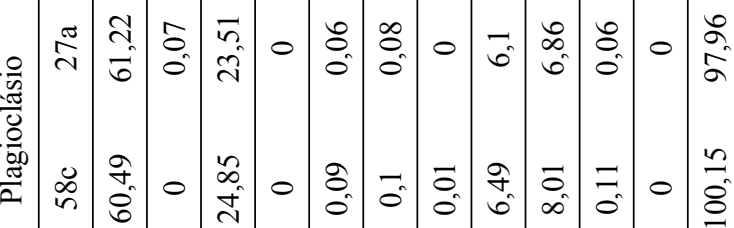

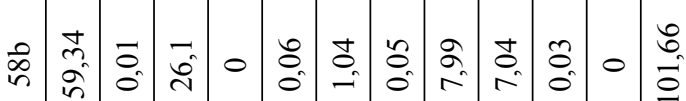

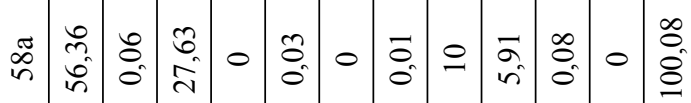

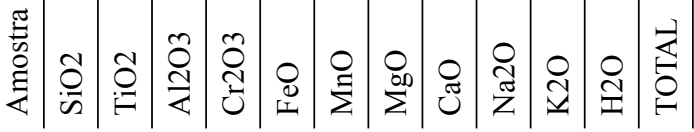

labradorita

b) $\left(\begin{array}{llll}\left.\mathrm{Ab}_{43} \mathrm{An}_{57}\right) & \left(\mathrm{Na}_{0.43}\right. & \mathrm{Ca}_{0.57}\end{array}\right)\left[\begin{array}{lll}\mathrm{Al}_{1.55} & \mathrm{Si}_{2.45} & \mathrm{O}_{8}\end{array}\right]-$

amostra 31:

$\left(\mathrm{Ab}_{48} \mathrm{An}_{52}\right)\left(\mathrm{Na}_{0.48} \mathrm{Ca}_{0.51} \mathrm{Mg}_{0.01}\right)\left[\begin{array}{lll}\mathrm{Al}_{1.50} & \mathrm{Si}_{2.50} & \mathrm{O}_{8}\end{array}\right]$ - labradorita

A variação composicional observada para os cristais de plagioclásio, por exemplo os da amostra 27 , pode ser eventualmente explicada pelo diferenciado grau de envolvimento dos mesmos em reações metamórficas ocorridas nestes diques. Em várias lâminas, os cristais de plagioclásio mostram-se algo sericitizados, epidotizados e, menos expressivamente, carbonatizados. Quando alterados intempericamente, transformam-se em minerais argilosos, vistos ao microscópio como uma massa escura.

Anfibólio Ocorre em substituição ao piroxênio. São cristais de hornblenda que se mostram, nas porções de borda dos diques, intensamente orientados, o que não acontece nas amostras do centro dos diques. Os cristais são, em sua maioria, hipidiomórficos e exibem um pleocroísmo em tons de verde e castanho. Em termos modais, estima-se corresponder entre 30-50\% do volume da rocha. As análises por microssonda eletrônica forneceram as seguintes fórmulas cristaloquímicas para os cristais de anfibólio:

\section{amostra 58:}

$\left(\mathrm{Na}_{0.54} \mathrm{~K}_{0.17} \mathrm{Ca}_{0.02}\right)\left(\mathrm{Ca}_{118.3} \mathrm{Fe}_{0.12} \mathrm{Mn}_{0.05}\right)$ $\left(\mathrm{Fe}_{2.93} \mathrm{Mg}_{1.22} \mathrm{Al}_{0.74}^{0.17} \mathrm{Ti}_{0.11}\right)^{2}\left[\mathrm{Al}_{1.71} \mathrm{Si}_{6.29} \mathrm{O}_{22}(\mathrm{OH})_{2}\right]-$ ferro(magnesio)-hornblenda

\section{amostra 27:} $\left(\mathrm{Mg}_{2.42} \mathrm{Fe}_{2,11} \mathrm{Al}_{0.37} \mathrm{Ti}_{0.09} \mathrm{Cr}_{0.01}{ }^{0}\right)\left[\mathrm{Al}_{0.83}^{0.06} \mathrm{Si}_{7.17} \mathrm{O}_{22}\left(\mathrm{OH}_{2}\right)\right]-$ magnésio(ferro)-hornblenda

\section{amostra 31:}

$\left(\mathrm{Na}_{0.33} \mathrm{~K}_{0.08} \mathrm{Ca}_{0.03}\right)\left(\mathrm{Ca}_{1.8 .2} \mathrm{Fe}_{0.14} \mathrm{Mn}_{0.02}\right)$ $\left(\mathrm{Mg}_{2,37} \mathrm{Fe}_{1.93} \mathrm{Al}_{0.63} \mathrm{Ti}_{0.07}\right)\left[\mathrm{Al}_{1.24} \mathrm{Si}_{6.76}^{8.2} \mathrm{O}_{22}(\mathrm{OH})_{2}\right]-$ magnésio(ferro)-hornblenda

Parece haver um predomínio da hornblenda rica em $\mathrm{Mg}$ sobre aquela rica em Fe. Raramente aparecem cristais fibrosos, provavelmente de tremolita-actinolita, substituindo o piroxênio.

Piroxênio Aparece como cristais reliquiares xenomorfos, remanescentes da mineralogia original, às vezes geminados, ou em massas de pequenos cristais recristalizados (poligonais) na maior parte das lâminas. Invariavelmente, os cristais mostram-se quase completamente substituídos por hornblenda. Por isto, perfazem menos de 5\% do volume da rocha nas lâminas contendo amostras da borda dos diques podendo, entretanto, chegar a 30\% nas amostras da parte central dos mesmos, onde a referida substituição é menos pronunciada. As análises por microssonda eletrônica forneceram a composição em termos de (Wo,En,Fs) e a fórmula cristaloquímica a seguir indicada:

\section{amostra 27:}

$\left(\mathrm{Wo}_{0,43} \mathrm{En}_{0,34} \mathrm{Fs}_{0,23}\right)-\left(\mathrm{Ca}_{0,82} \mathrm{Mg}_{0,66} \mathrm{Fe}^{2+}{ }_{0,44} \mathrm{Al}_{0,05} \mathrm{Na}_{0,0}\right.$ $\left.{ }_{2} \mathrm{Ti}_{0,01}\right)\left[\left(\mathrm{Si}_{1,97} \mathrm{Al}_{0,03}{ }^{0,34} \mathrm{O}_{6}\right]\right.$ - augita 
Granada Aparece, na maioria das vezes, na forma de coronas (Fig. 7), normalmente na interface entre cristais de plagioclásio e augita, parecendo resultar da reação entre estes dois minerais. É facilmente identificada por sua isotropia sob nicóis cruzados, apesar de normalmente não representar mais de $2-3 \%$ do volume total da rocha. A análise por microssonda eletrônica forneceu a fórmula cristaloquímica a seguir:

\section{amostra 27:} mandina

$\left(\mathrm{Fe}_{2,00} \mathrm{Ca}_{0,63} \mathrm{Mg}_{0,27} \mathrm{Mn}_{0,10}\right) \mathrm{Al}_{2}\left(\mathrm{Si}_{2,98} \mathrm{Al}_{0,02}\right) \mathrm{O}_{12}$ - al-

Minerais Opacos Ocorrem como agregados de pequenos cristais hipidiomórficos ou esqueléticos, normalmente no interior de massas de hornblenda. Às vezes, é percebida a presença de leucoxênio (e raramente titanita) junto a estes opacos, cuja composição, determinada por microssonda, confirmou a sua prévia identificação microscópica como ilmenita. Aparentemente, os minerais opacos não são de origem metamórfica (cristalizaram-se anteriormente ao metamorfismo sofrido pelos diques) e perfazem cerca de $5 \%$ do volume total da rocha.

amostra 27:

$\left(\mathrm{Fe}_{0.94} \mathrm{Mn}_{0.05} \mathrm{Mg}_{0.01}\right) \mathrm{TiO}_{3}$ - ilmenita

\section{amostra 31:}

$\left(\mathrm{Fe}_{0.91} \mathrm{Mn}_{0.07} \mathrm{Mg}_{0.01} \mathrm{Ca}_{0.01}\right) \mathrm{TiO}_{3}$ - ilmenita

\section{amostra 58:}

$\left(\mathrm{Fe}_{0.97} \mathrm{Mn}_{0.03}\right) \mathrm{TiO}_{3}$ - ilmenita

Biotita e Clorita Biotita primária aparece acessoriamente (menos de $3 \%$ do volume da rocha) com hábito tabular e cores de interferência típicas, em tons de vermelho e verde. Sagenita, ou seja, rutilo acicular oriundo de exsolução no interior de alguns grão de biotita, pode ser verificada em algumas amostras. $\mathrm{Na}$ maior parte das lâminas, porém, a biotita encontra-se quase sempre substituída por clorita, esta última facilmente

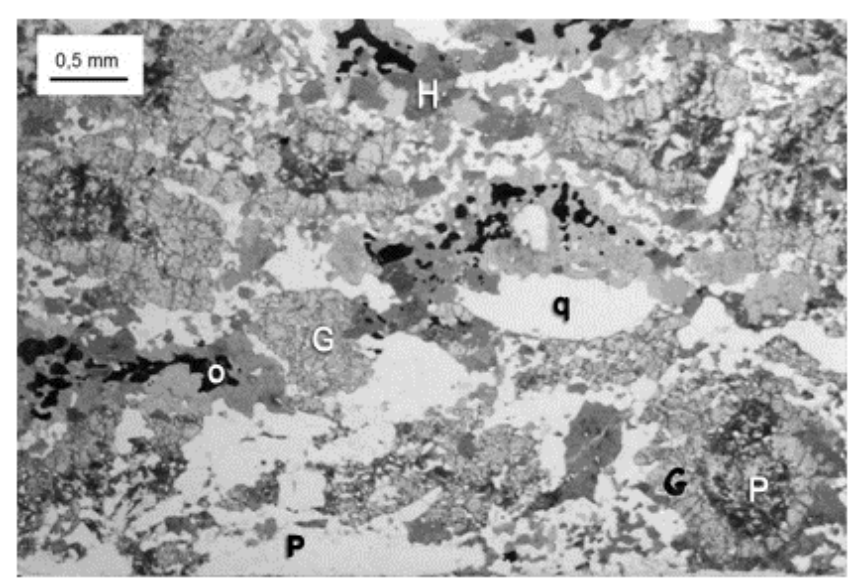

Figura 7 - Coronas de granada $(G)$ ao redor de cristais alterados de plagioclásio (P), sob nicóis cruzados. $H$ $=$ hornblenda, $O=$ opacos (ilmenita), $q=$ quartzo. identificável por sua cor de interferência anômala (em tons roxo esverdeados). Alguns grãos de clorita foram analisados por microssonda eletrônica e os resultados levaram às seguintes fórmulas cristaloquímicas:

\section{amostra 58: \\ $\left(\mathrm{Fe}_{2.86} \mathrm{Mg}_{1.79} \mathrm{Al}_{1.22} \mathrm{Ti}_{0.05} \mathrm{Na}_{0.03} \mathrm{Ca}_{0.02} \mathrm{Mn}_{0.02} \mathrm{~K}_{0.01}\right)$ $\left[\mathrm{Al}_{0.98} \mathrm{Si}_{3.02} \mathrm{O}_{10}(\mathrm{OH})_{8}\right]$ - chamosita \\ amostra 31: \\ $\left(\mathrm{Fe}_{2.02} \mathrm{Mg}_{2.34} \mathrm{Al}_{1.09} \mathrm{Ca}_{0.24} \mathrm{Ti}_{0.19} \mathrm{Mn}_{0.09} \mathrm{~K}_{0.03}\right)$ $\left[\mathrm{Al}_{1.05} \mathrm{Si}_{2.95} \mathrm{O}_{10}(\mathrm{OH})_{8}\right]$ - clinocloro}

Sericita Aparece em substituição ao plagioclásio e sua proporção, em termos do volume da rocha, varia de acordo com o estado de alteração de cada amostra. Em geral, não chega a representar mais de $5 \%$ do volume total. Mostra-se como uma massa de pequenos cristais fibrosos de elevada birrefringência no interior dos cristais de plagioclásio.

Epidoto Aparece também em substituição ao plagioclásio, na forma de pequenos agregados ou isoladamente, com seu pleocroísmo amarelo esverdeado a verde. É notada também a presença de clinozoisita, distinguida do epidoto por sua birrefringência mais baixa e ausência de pleocroísmo. Em geral, o epidoto e a clinozoisita chegam a constituir $5 \%$ do volume total da rocha.

Carbonato Em algumas lâminas é notada a presença de calcita, facilmente identificada pela sua cintilância em tons róseos, verdes e azuis, em luz polarizada. Ela aparece também como produto de substituição do plagioclásio, principalmente quando este é mais cálcico. Usualmente não ultrapassa $2 \%$ do volume da rocha.

Quartzo Ocorre como mineral subordinado, correspondendo a cerca de $1-2 \%$ do volume da rocha. Como os opacos, aparece associado à hornblenda na maior parte das vezes.

Zircão Aparece acessoriamente, representando menos de $1 \%$ do volume da rocha. Geralmente encontra-se metamíctico no interior dos cristais de hornblenda, com nítido halo pleocroico circundando-o. Nas porções centrais dos diques, os cristais de zircão mostram-se normalmente prismáticos, enquanto nas bordas, onde o metamorfismo e a deformação foram mais intensos, aparentemente encontram-se recristalizados.

LITOGEOQUÍMICA Os resultados das análises químicas dos anfibolitos estudados, realizadas em rocha total na Ecole des Mines de Saint-Etienne (França), encontram-se na tabela 2.

Uma vez que os diques de anfibolito Paraopeba mostram feições de deformação com recristalização associada, conforme apontaram os estudos petrográficos, é necessária a investigação sobre a possibilidade de mobilização de certos elementos químicos como fruto da atuação de processos metamórfico-hidrotermais sinou pós-magmáticos. 
O comportamento dos elementos químicos em processos que incluem uma fase fluida depende das suas propriedades químicas, em particular, dos potenciais iônicos dos elementos (potencial iônico $=$ carga/ raio), os quais acabam por controlar suas mobilidades em fluidos. De acordo com esse critério, podem ser considerados como relativamente imóveis, ou seja, capazes de manter registradas as características dos magmas originais, o Ti, $\mathrm{Zr}, \mathrm{Nb}, \mathrm{Ta}, \mathrm{Y}, \mathrm{Cr}$, Th, elementos terras-raras (exceto o La) e, possivelmente o P. Sob condições metamórficas pertencentes à facies anfibolito a xisto verde, os elementos de baixo (e.g. $\mathrm{Na}, \mathrm{Mg}, \mathrm{K}$, $\mathrm{Ca}, \mathrm{Ni}, \mathrm{Rb}, \mathrm{Sr}, \mathrm{Ba}$ e La) e de alto (e.g. Si) potencial podem ser mobilizados por meio de soluções aquecidas, em particular em zonas de cisalhamento (Winchester \& Floyd 1976).

Tabela 2 - Análises químicas dos anfibolitos. Os óxidos de elementos maiores são dados em \% de peso, enquanto os elementos traços e os terras-raras (ETR) são dados em ppm. Ferro expresso como $\mathrm{FeO}_{T}$

\begin{tabular}{|c|c|c|c|c|c|c|c|c|c|c|c|c|c|c|c|c|c|c|c|c|c|}
\hline Amostra & $\mathrm{SiO} 2$ & $\mathrm{TiO} 2$ & $\mathrm{~A} 12 \mathrm{O} 3$ & $\mathrm{FeO}$ & $\mathrm{MnO}$ & $\mathrm{MgO}$ & $\mathrm{CaO}$ & $\mathrm{Na} 2 \mathrm{O}$ & $\mathrm{K} 2 \mathrm{O}$ & $\mathrm{P} 2 \mathrm{O} 5$ & LOI & TOTAL & $\mathrm{Mg} \#$ & $\mathrm{Ni}$ & $\mathrm{Rb}$ & $\mathrm{Ba}$ & $\mathrm{Sr}$ & $\mathrm{Nb}$ & $\mathrm{Hf}$ & $\mathrm{Zr}$ & Y \\
\hline CON1 & 47,51 & 1,68 & 13,78 & 14,16 & 0,22 & 5,75 & 9,97 & 3,2 & 0,55 & 0,2 & 1,32 & 98,34 & 46 & 64 & 19 & 161 & 120 & 9 & 13,6 & 108 & 43 \\
\hline CON6 & 44,82 & 2,54 & 13,9 & 15,8 & 0,22 & 6,08 & 9,41 & 2,1 & 0,79 & 0,48 & 2,45 & 98,59 & 44,7 & 98 & 28 & 215 & 130 & 11,8 & 11,9 & 197 & 41 \\
\hline CON10 & 49,01 & 1,16 & 13,22 & 13,59 & 0,22 & 5,98 & 10,14 & 2,31 & 0,42 & 0,09 & 2,02 & 98,16 & 48 & 44 & 14 & 86 & 125 & 4,3 & 10,2 & 65 & 29 \\
\hline CON14 & 47,77 & 1,66 & 13,35 & 13,74 & 0,22 & 6,24 & 10,79 & 2,31 & 0,53 & 0,14 & 1,26 & 98,01 & 48,8 & 77 & 25 & 105 & 92 & 6,4 & 10,3 & 79 & 40 \\
\hline CON15 & 48,21 & 1,6 & 14,15 & 13,5 & 0,21 & 6,13 & 10,14 & 2,81 & 0,37 & 0,17 & 0,57 & 97,86 & 48,8 & 79 & 12 & 111 & 117 & 6 & 14,7 & 93 & 33 \\
\hline CON 15X & 49,76 & 1,45 & 13,88 & 14,61 & 0,21 & 5,75 & 10,18 & 2,52 & 0,41 & 0,13 & 0,15 & 99,05 & 45,2 & 63 & 14 & 96 & 106 & 6,6 & 10,8 & 90 & 34 \\
\hline CON22 & 48,08 & 1,46 & 13,17 & 13,87 & 0,22 & 6,07 & 10,29 & 2,78 & 0,61 & 0,14 & 1,51 & 98,21 & 47,9 & 60 & 26 & 108 & 109 & 6 & 10,6 & 83 & 33 \\
\hline CON29 & 48,69 & 1,93 & 13,44 & 14,48 & 0,21 & 5,57 & 9,88 & 2,87 & 0,63 & 0,2 & 0,41 & 98,31 & 44,7 & 62 & 21 & 136 & 100 & 7,9 & 13 & 114 & 43 \\
\hline CON31 & 46,3 & 2,54 & 10,94 & 17,62 & 0,25 & 6,06 & 9,53 & 1,98 & 0,73 & 0,17 & 1,38 & 97,5 & 41,9 & 76 & 29 & 149 & 106 & 8 & 13,3 & 90 & 40 \\
\hline CON33 & 48,09 & 1,45 & 14,18 & 13,58 & 0,21 & 5,66 & 9,96 & 2,19 & 0,71 & 0,13 & 1,62 & 97,78 & 46,7 & 65 & 35 & 105 & 102 & 6,3 & 13 & 85 & 33 \\
\hline ESM2 & 50,24 & 2,14 & 12,62 & 17,04 & 0,23 & 3,52 & 8,24 & 3,51 & 0,51 & 0,34 & 0,3 & 98,69 & 30,2 & 35 & 11 & 130 & 130 & 10,3 & 12,9 & 169 & 50 \\
\hline ESM4 & 45,6 & 0,73 & 14,89 & 10,02 & 0,17 & 9,2 & 11,04 & 1,99 & 0,53 & 0,07 & 2,26 & 96,5 & 65,8 & 169 & 27 & 109 & 156 & 2,2 & 9,5 & 33 & 16 \\
\hline ESM 5M & 52,71 & 2,08 & 14,58 & 14,23 & 0,19 & 2,27 & 7,06 & 3,3 & 1,2 & 0,54 & 0,83 & 99 & 25,1 & 11 & 38 & 298 & 263 & 14,8 & 10,6 & 413 & 70 \\
\hline ESM 7 & 48,63 & 1,77 & 13,71 & 14,12 & 0,21 & 6,65 & 9,17 & 2,46 & 1,74 & 0,23 & 1,5 & 100,19 & 49,7 & 68 & 39 & 187 & 142 & 7,8 & 4,4 & 129 & 36 \\
\hline ESM 9A & 47,61 & 2,09 & 13,03 & 15,52 & 0,22 & 6,18 & 9,01 & 2,69 & 1,26 & 0,26 & 1,36 & 99,23 & 45,5 & 54 & 61 & 231 & 161 & 7,3 & 7,8 & 137 & 39 \\
\hline 22 & 48,9 & 1,46 & 13,79 & 13,84 & 0,21 & 6,35 & 10,38 & 2,55 & 0,63 & 0,13 & 0,84 & 99,08 & 49,1 & 60 & 32 & 98 & 123 & 5,6 & 5,9 & 98 & 32 \\
\hline 27 & 47,48 & 2,04 & 14,91 & 14,66 & 0,19 & 4,82 & 9,34 & 2,41 & 1,14 & 0,23 & 1,81 & 99,03 & 40,8 & 42 & 50 & 203 & 193 & 8,3 & 6 & 126 & 28 \\
\hline 28 & 48,75 & 1,15 & 14,18 & 13,69 & 0,2 & 6,84 & 10 & 2,52 & 0,61 & 0,11 & 1,33 & 99,39 & 51,2 & 78 & 22 & 84 & 161 & 4,6 & 3,2 & 84 & 21 \\
\hline 29 & 47,7 & 1,26 & 14,73 & 13,32 & 0,19 & 6,97 & 10,35 & 2,58 & 0,42 & 0,11 & 1,4 & 99,03 & 52,3 & 95 & 13 & 77 & 148 & 7 & 4 & 88 & 25 \\
\hline 31 & 48,04 & 1,23 & 14,52 & 13,67 & 0,2 & 7,4 & 10,07 & 2,07 & 0,77 & 0,12 & 1,29 & 99,38 & 53,2 & 92 & 30 & 133 & 133 & 6 & 6 & 90 & 26 \\
\hline 38 & 49 & 1,93 & 12,9 & 15,67 & 0,22 & 5,33 & 9,62 & 2,33 & 0,94 & 0,18 & 1,32 & 99,44 & 41,6 & 41 & 41 & 170 & 121 & 5,9 & 8,2 & 132 & 40 \\
\hline 39 & & 1,64 & 15,36 & 13 & 0,19 & 6,4 & 9,94 & 2,1 & 0,92 & 0,19 & 1,25 & 99,38 & 50 & 78 & 37 & 178 & 132 & 7,4 & 5,3 & 133 & 37 \\
\hline 46 & 45,81 & 3,05 & 12,75 & 18,57 & 0,21 & 5,44 & 8,74 & 2,02 & 1,03 & 0,34 & 1,52 & 99,48 & 38,1 & 53 & 34 & 290 & 127 & 9,6 & 8,3 & 193 & 46 \\
\hline 53 & 49,84 & 1 & 14,51 & 12,5 & 0,2 & 7,57 & 11,07 & 2,74 & 0,33 & 0,1 & 0,27 & 100,58 & 55,1 & 90 & 11 & 59 & 99 & 4,6 & 4,4 & 68 & 23 \\
\hline 56 & 49,84 & 1,47 & 12,17 & 15,63 & 0,23 & 6,33 & 9,33 & 2,37 & 0,63 & 0,19 & 0,78 & 98,97 & 45,9 & 65 & 29 & 82 & 128 & 6,8 & 5,9 & 124 & 33 \\
\hline 58 & 50,89 & 2,32 & 14,27 & 16,82 & 0,22 & 3,23 & 8,27 & 3,53 & 0,75 & 0,31 & 0,5 & 101,1 & 28,7 & 23 & 29 & 178 & 167 & 12,7 & 7,6 & 212 & 44 \\
\hline 73 & 48,69 & 1,99 & 13,32 & 14,81 & 0,21 & 5,99 & 8,77 & 2,43 & 0,85 & 0,25 & 0,97 & 98,28 & 45,9 & 43 & 45 & 168 & 131 & 7,9 & 4,5 & 127 & 35 \\
\hline 81 & 48,7 & 1,88 & 15,12 & 14,23 & 0,2 & 5,21 & 9,59 & 2,4 & 0,76 & 0,23 & 1,16 & 99,48 & 43,4 & 47 & 24 & 163 & 171 & 7,6 & 4,6 & 127 & 36 \\
\hline 90 & 48,42 & 1,22 & 14,47 & 13,59 & 0,2 & 7,3 & 10,29 & 1,98 & 0,46 & 0,11 & 1,1 & 99,14 & 53 & 91 & 18 & 82 & 138 & 6,1 & 3,4 & 88 & 26 \\
\hline 119 & 47,56 & 1,18 & 17,26 & 13,11 & 0,18 & 4,89 & 10,68 & 2,3 & 0,4 & 0,15 & 2,03 & 99,74 & 43,9 & 69 & 14 & 75 & 149 & 5,9 & 3,7 & 97 & 29 \\
\hline 130 & 49,3 & 1,88 & 12,85 & 15,93 & 0,23 & 5,73 & 9,04 & 2,24 & 0,92 & 0,17 & 1,12 & 99,42 & 43 & 45 & 39 & 474 & 125 & 4,1 & 7 & 121 & 52 \\
\hline 138 & 50,38 & 1,13 & 14,14 & 13,8 & 0,21 & 7,28 & 10,85 & 2,08 & 0,33 & 0,11 & 0,68 & 100,99 & 52,5 & 97 & 11 & 61 & 104 & 5,7 & 3,3 & 85 & 27 \\
\hline 145 & 50,29 & 1,27 & 13,79 & 13,36 & 0,21 & 7,23 & 10,44 & 2,44 & 0,5 & 0,12 & 0,78 & 100,44 & 53,2 & 85 & 20 & 84 & 118 & 5 & 4,6 & 87 & 29 \\
\hline 148 & 49,56 & 1,3 & 13,87 & 14,44 & 0,22 & 6,73 & 10,47 & 2,28 & 0,35 & 0,13 & 0,87 & 100,23 & 49,4 & 73 & 8 & 350 & 109 & 6,1 & 6,3 & 92 & 31 \\
\hline 153 & 48,48 & 2,51 & 12,29 & 17,47 & 0,26 & 5,24 & 7,99 & 3,6 & 1,54 & 0,31 & 1,53 & 101,22 & 38,6 & 37 & 79 & 350 & 103 & 9,6 & 7,8 & 194 & 60 \\
\hline $165 \mathrm{~B}$ & 49,06 & 1,51 & 13,69 & 15,26 & 0,23 & 6,8 & 8,49 & 2,34 & 1,07 & 0,12 & 1,7 & 100,27 & 48,3 & 65 & 65 & 142 & 113 & 5,1 & 6 & 94 & 33 \\
\hline 176 & 50,07 & 1,76 & 13,31 & 14,56 & 0,23 & 6,76 & 9,75 & 2 & 0,81 & 0,2 & 1,37 & 100,82 & 49,3 & 47 & 48 & 173 & 125 & 7,9 & 6,3 & 124 & 31 \\
\hline 181 & 49,62 & 1,78 & 13,26 & 15,08 & 0,22 & 6,12 & 9,94 & 2,09 & 0,47 & 0,19 & 0 & 98,77 & 46 & 57 & 14 & 102 & 117 & 8,2 & 6,3 & 131 & 39 \\
\hline 189 & 49,44 & 1,8 & 15,55 & 13,73 & 0,19 & 4,5 & 9,03 & 1,96 & 1,04 & 0,21 & 1,68 & 99,13 & 40,7 & 40 & 61 & 164 & 160 & 8,5 & 6,6 & 140 & 43 \\
\hline 194 & 47,17 & 1,38 & 14,29 & 14,69 & 0,2 & 6,48 & 9,39 & 1,99 & 0,49 & 0,13 & 2,45 & 98,66 & 48,1 & 85 & 26 & 410 & 192 & 2,6 & 6,3 & 96 & 75 \\
\hline
\end{tabular}


Tabela 2 continuação

\begin{tabular}{lcccccccccccc}
\hline Amostra & $\mathrm{La}$ & $\mathrm{Ce}$ & $\mathrm{Nd}$ & $\mathrm{Sm}$ & $\mathrm{Eu}$ & $\mathrm{Gd}$ & $\mathrm{Dy}$ & $\mathrm{Yb}$ & $(\mathrm{La} / \mathrm{Yb}) \mathrm{n}$ & $(\mathrm{La} / \mathrm{Sm}) \mathrm{n}$ & $(\mathrm{Gd} / \mathrm{Yb}) \mathrm{n}$ & $(\mathrm{Eu} / \mathrm{Eu}) \mathrm{n}$ \\
\hline CON1 & 12,6 & 27,5 & 18 & 5,6 & 1,63 & 7,15 & 7,55 & 4,08 & 2,08 & 1,42 & 1,42 & 0,79 \\
\hline CON6 & 18,4 & 42,8 & 26,9 & 6,48 & 2,15 & 7,89 & 7,82 & 4,01 & 3,1 & 1,79 & 1,59 & 0,92 \\
\hline CON10 & 7,21 & 17,9 & 11,1 & 3,38 & 1,15 & 4,87 & 5,27 & 2,99 & 1,63 & 1,34 & 1,32 & 0,87 \\
\hline CON14 & 9,79 & 23,1 & 15,3 & 4,54 & 1,4 & 6,35 & 6,74 & 3,7 & 1,79 & 1,36 & 1,39 & 0,8 \\
\hline CON15 & 10,2 & 23,7 & 15,2 & 4,14 & 1,37 & 5,66 & 6,03 & 3,34 & 2,06 & 1,55 & 1,37 & 0,87 \\
\hline CON 15X & 11,4 & 27,2 & 17,1 & 4,6 & 1,39 & 6,14 & 6,5 & 3,46 & 2,22 & 1,56 & 1,43 & 0,8 \\
\hline CON22 & 10,2 & 24,5 & 15,3 & 4,21 & 1,27 & 5,7 & 6,05 & 3,2 & 2,15 & 1,53 & 1,44 & 0,79 \\
\hline CON29 & 13,9 & 31,9 & 19,3 & 5,78 & 1,68 & 7,05 & 7,59 & 4,29 & 2,19 & 1,51 & 1,33 & 0,8 \\
\hline CON31 & 13,1 & 24,7 & 16,9 & 5,66 & 1,62 & 6,87 & 7,34 & 3,88 & 2,28 & 1,46 & 1,43 & 0,79 \\
\hline CON33 & 10,3 & 23,6 & 14,6 & 4,29 & 1,31 & 5,5 & 5,86 & 3,33 & 2,09 & 1,51 & 1,33 & 0,82 \\
\hline ESM2 & 18,2 & 42,6 & 28,1 & 7,41 & 2,25 & 9,06 & 8,87 & 4,41 & 2,79 & 1,55 & 1,66 & 0,84 \\
\hline ESM4 & 3,5 & 7,79 & 5,21 & 2,06 & 0,7 & 3,09 & 2,95 & 1,71 & 1,38 & 1,07 & 1,46 & 0,85 \\
\hline
\end{tabular}

Segundo Juliani \& McReath (1992), dentre os métodos que têm sido propostos para investigar a mobilidade de elementos químicos, o mais difundido, e originalmente desenvolvido por Pearce (1968) para interpretar tendências de fracionamento em suítes ígneas inalteradas, foi posteriormente adaptado (Beswick 1982) para avaliar os efeitos de alteração ou metamorfismo em amostras de komatiitos e basaltos. Ele consiste em verificar se um determinado elemento segue as tendências de processos magmáticos: em caso positivo é dito imóvel; caso contrário trata-se de um mobilizado. No caso de se investigar elementos maiores, um método que pode fornecer resultados satisfatórios é aquele que se utiliza das razões de proporções moleculares ou MPR (Molecular Proportion Ratios).

O método propõe a avaliação dos elementos maiores através da correlação entre razões do tipo $\mathrm{A} / \mathrm{N}$ (x) e $\mathrm{B} / \mathrm{N}(\mathrm{y})$, onde as proporções moleculares dos óxidos A e B (normalizados) participam das fases fracionadas, enquanto o elemento $\mathrm{N}$ (normalizador) seria uma constante no decurso do fracionamento, comportando-se como incompatível. Se não ocorrer tendência de correlação linear, mas sim um espalhamento dos pontos segundo um arranjo em leque a partir da origem dos eixos x e y, pode-se considerar a mobilidade do elemento normalizador, pressupondo-se como relativamente imóveis os dois óxidos normalizados.

Assim, na tentativa de investigar até que ponto os diques Paropeba tiveram suas composições obliteradas, foram construídos os diagramas MPR da figura 8. O elemento normalizador escolhido foi o $\mathrm{Zr}$, sabidamente incompatível, enquanto que os óxidos selecionados, cujos elementos participam das fases fracionadas, foram $\mathrm{SiO}_{2}$ (parâmetro), $\mathrm{Al}_{2} \mathrm{O}_{3}, \mathrm{FeO}_{\mathrm{T}}, \mathrm{MgO}, \mathrm{CaO}, \mathrm{Na}_{2} \mathrm{O}$ e $\mathrm{K}_{2} \mathrm{O}$. Os óxidos $\mathrm{TiO}_{2}$ e $\mathrm{P}_{2} \mathrm{O}_{5}$ não foram lançados, pois Ti e P normalmente são imóveis no metamorfismo.

$\mathrm{Na}$ apuração das informações fornecidas por esses diagramas, inicialmente pode ser confirmada a imobilidade do elemento normalizador $\mathrm{Zr}$, dada a tendência de correlação linear na maior parte dos diagramas MPR. Esses alinhamentos nos diagramas $\mathrm{SiO}_{2} / \mathrm{Zr}$
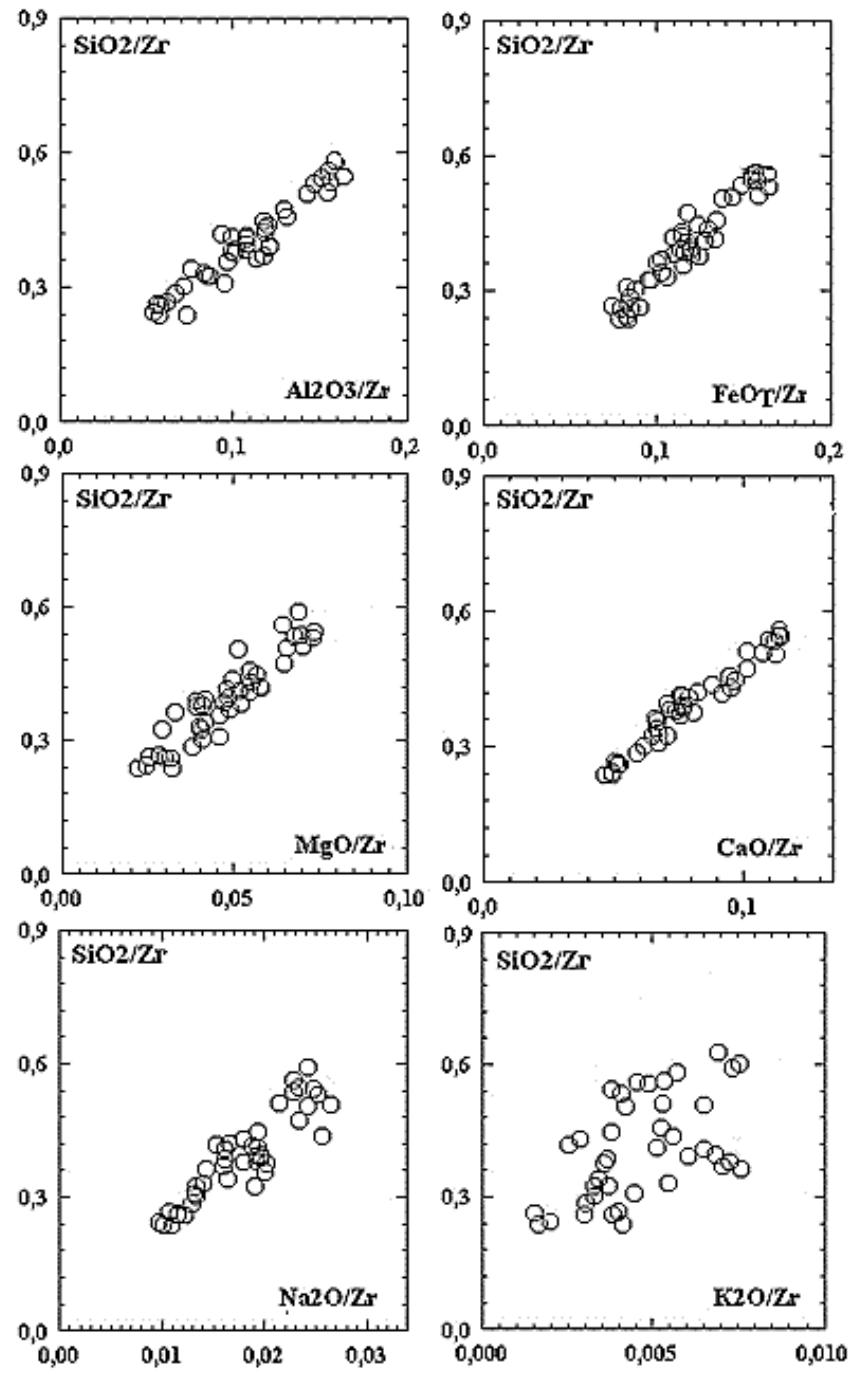

Figura 8 - Diagramas de razões de proporções moleculares (MPR - Pearce 1968) dos anfibolitos Paraopeba. 
versus $\mathrm{Al}_{2} \mathrm{O}_{3} / \mathrm{Zr}, \mathrm{FeO}_{\mathrm{T}} / \mathrm{Zr}, \mathrm{MgO} / \mathrm{Zr}, \mathrm{CaO} / \mathrm{Zr}$ e $\mathrm{Na}_{2} \mathrm{O} / \mathrm{Zr}$ mostram que os elementos $\mathrm{Si}, \mathrm{Al}, \mathrm{Fe}, \mathrm{Mg}, \mathrm{Ca}$ e $\mathrm{Na}$, os mais importantes no processo de fracionamento, praticamente não foram mobilizados no metamorfismo sofrido pelos diques Paraopeba. Já os padrões em leque percebidos nos diagramas $\mathrm{SiO}_{2} / \mathrm{Zr}$ versus $\mathrm{K}_{2} \mathrm{O} / \mathrm{Zr}$ apontam para a mobilização de $\mathrm{K}$ no metamorfismo.

Estas observações, apesar da provável mobilização do K, permitem seguramente prosseguir no tratamento dos dados químicos, que se inicia com a averiguação do caráter ortoderivado dos diques através do diagrama ferro-titânio $\left(\mathrm{FeO}_{\mathrm{T}}\right.$ versus $\mathrm{TiO}_{2}$, ambos em \% em peso) exposto na figura 9 .

Na classificação petrográfica com base química, segundo o diagrama TAS (total de álcalis versus sílica) de Cox et al. (1979), os diques de anfibolito estudados correspondem, em sua maioria, a basaltos subalcalinos (Fig. 10).

No diagrama R1 x R2 (De La Roche et al. 1980), os anfibolitos situam-se nos campos dos basaltos toleíticos e transicionais (Fig. 11) e nenhum deles chega a ser um álcali-basalto.

O caráter toleítico dos diques anfibolíticos é confirmado através do posicionamento dos mesmos no diagrama ternário AFM (Irvine \& Baragar 1971), onde $\mathrm{A}=\mathrm{Na}_{2} \mathrm{O}+\mathrm{K}_{2} \mathrm{O}$ (álcalis), $\mathrm{F}=\mathrm{FeO}_{\mathrm{T}}$ e $\mathrm{M}=\mathrm{MgO}$, que separa as séries toleítica e cálcio-alcalina. Neste diagrama, todos os diques mostram tendência de diferenciação no campo dos toleítos (Fig. 12).

Em termos das composições normativas CIPW, os protólitos dos anfibolitos analisados variam de quartzo-toleítos (supersaturados em sílica) a olivina-toleítos (saturados em sílica), chegando até a álcali-olivina basaltos (subsaturado em sílica), conforme mostra o diagrama Ne-Ol-Di, Ol-Di-Hy, Di-Hy-Q da figura 13. Esta variação reflete o processo de diferenciação magmática anterior ao metamorfismo, já previamente revelado pela presença de antigos fenocristais de plagioclásio deformacionalmente rotacionados no interior de alguns diques.

Cerca de $90 \%$ dos valores do número de magnésio $\left[\mathrm{Mg} \#=\mathrm{Mg}^{+2} /\left(\mathrm{Mg}^{+2}+\mathrm{Fe}^{+2}\right)\right.$, razão molar $]$ encontram-se entre 40 e 55, indicando evolução moderada dos magmas antes da intrusão. Nos diagramas binários de variação de óxidos de elementos maiores ou dos traços em função do Mg \# (Figs. 14 e 15), a diferenciação magmática se destaca. Neles é notada a existência de alinhamentos bem definidos (por exemplo, $\mathrm{TiO}_{2}, \mathrm{FeO}, \mathrm{CaO}, \mathrm{K}_{2} \mathrm{O}, \mathrm{P}_{2} \mathrm{O}_{5}, \mathrm{Ni}$, $\mathrm{Rb}, \mathrm{Ba}, \mathrm{Nb}, \mathrm{Zr}, \mathrm{Y}$ ), derivados do processo de diferenciação magmática, certamente por cristalização fracionada. De uma maneira geral, o decréscimo do Mg \# é acompanhado pelo decréscimo de $\mathrm{CaO}$ e $\mathrm{Ni}$ e pelo aumento de $\mathrm{TiO}_{2}, \mathrm{FeO}, \mathrm{Na}_{2} \mathrm{O}, \mathrm{K}_{2} \mathrm{O}, \mathrm{P}_{2} \mathrm{O}_{5}$ e elementos incompatíveis como $\mathrm{Rb}, \mathrm{Ba}, \mathrm{Nb}, \mathrm{Zr}$ e Y.

No diagrama de elementos incompatíveis normalizados ao manto (Fig. 16), os anfibolitos apresentam padrão semelhante àquele dos toleítos continentais de Holm (1985), com anomalia negativa de $\mathrm{Nb}$, que aponta para o envolvimento de crosta continental nos processos magmáticos e, portanto, típica da maioria dos basaltos toleíticos continentais. Uma pronunciada anomalia negativa de Sr também está evidenciada neste diagrama, que pode ser explicada pelo baixo grau de fusão da fonte mantélica do magma, que normalmente é enriquecida neste elemento, e/ou pelo fracionamento do plagioclásio.

$\mathrm{O}$ diagrama de elementos terras-raras (ETR) normalizados à condrito (Fig. 17) mostra, para os anfibolitos estudados, um padrão quase plano, com discreto

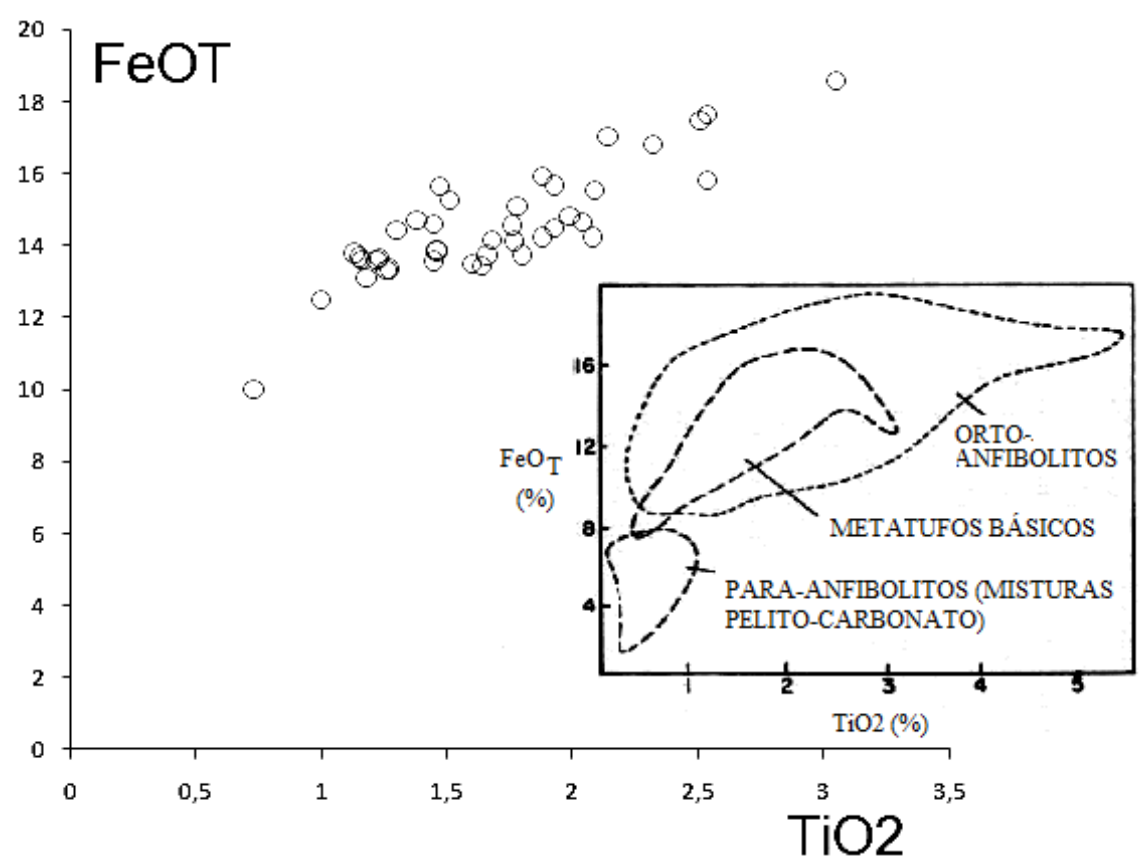

Figura 9 - Diagrama ferro-titânio discriminativo para ortoanfibolitos e paraanfibolitos (Peloggia \& Figueiredo 1991). Os diques de anfibolito Paraopeba situam-se no campo dos ortoanfibolitos. 


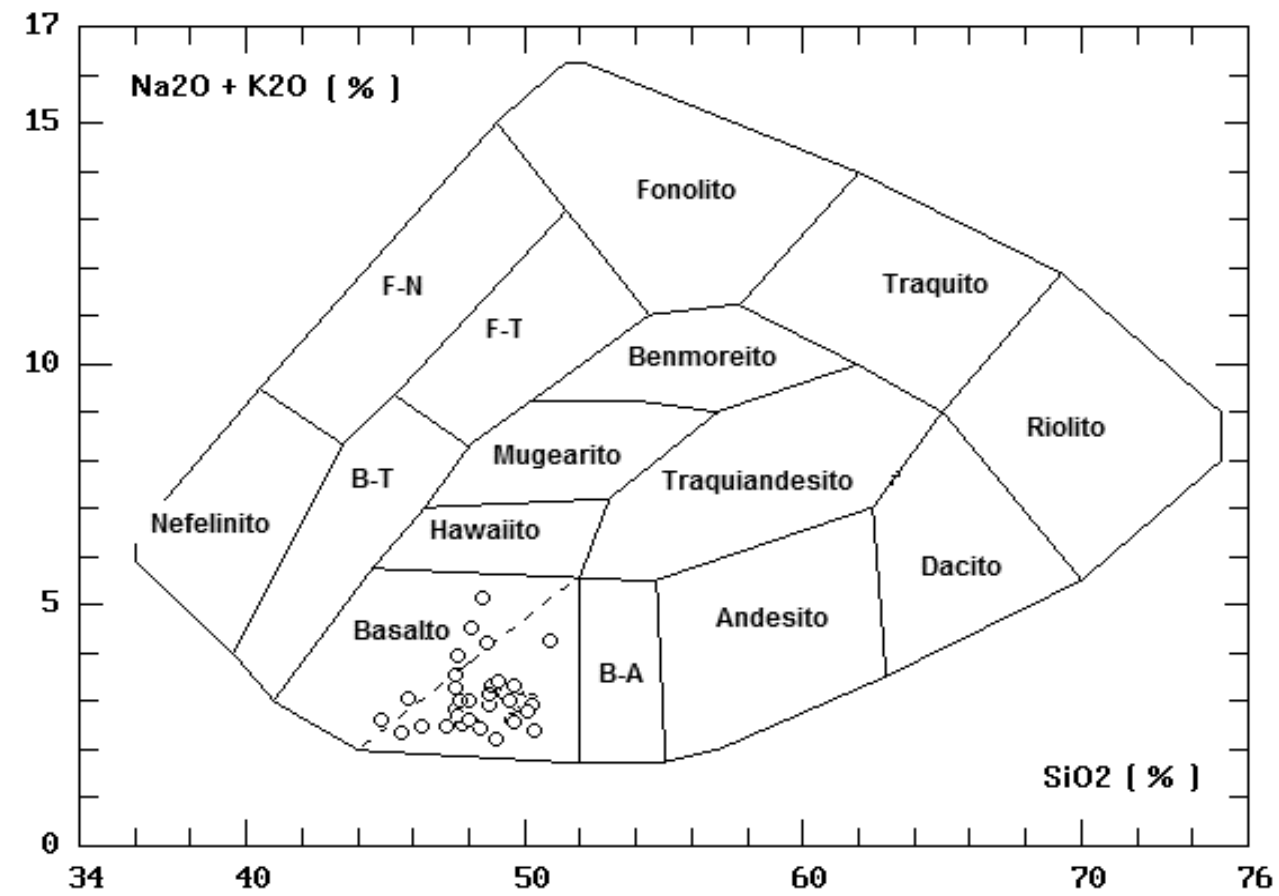

Figura 10 - Diagrama TAS (total de álcali versus sílica) de COX et al. (1979), onde os diques de anfibolito têm suas composições projetadas no campo dos basaltos subalcalinos (maioria) e basaltos alcalinos.

fracionamento de $\operatorname{ETR}\left[(\mathrm{La} / \mathrm{Yb})_{\mathrm{n}}=1,4-3,0, \quad(\mathrm{La} / \mathrm{Sm})\right.$ $\left.\mathrm{n}=1,1-1,8, \quad(\mathrm{Gd} / \mathrm{Yb})_{\mathrm{n}}=1,3-1,7\right]$. Uma fraca anomalia negativa de $\mathrm{Eu}\left[\left(\mathrm{Eu} / \mathrm{Eu}^{*}\right)_{\mathrm{n}}=0,8-0,9\right]$, devida, provavelmente, ao fracionamento do plagioclásio durante os processos de diferenciação magmática anteriores ao metamorfismo, pode ser observada na maioria das amostras analisadas.
GEOCRONOLOGIA Através de isócrona interna Rb-Sr de um dique Paraopeba relativamente indeformado (Tab. 3, Fig. 18), foi possível obter a idade de 2189 +/- 45 Ma. Esta idade permite inferir uma associação direta entre os diques de anfibolíto e as ZCT durante o evento compressivo transamazônico. Tal idade certamente indica o tempo de colocação do enxame e,

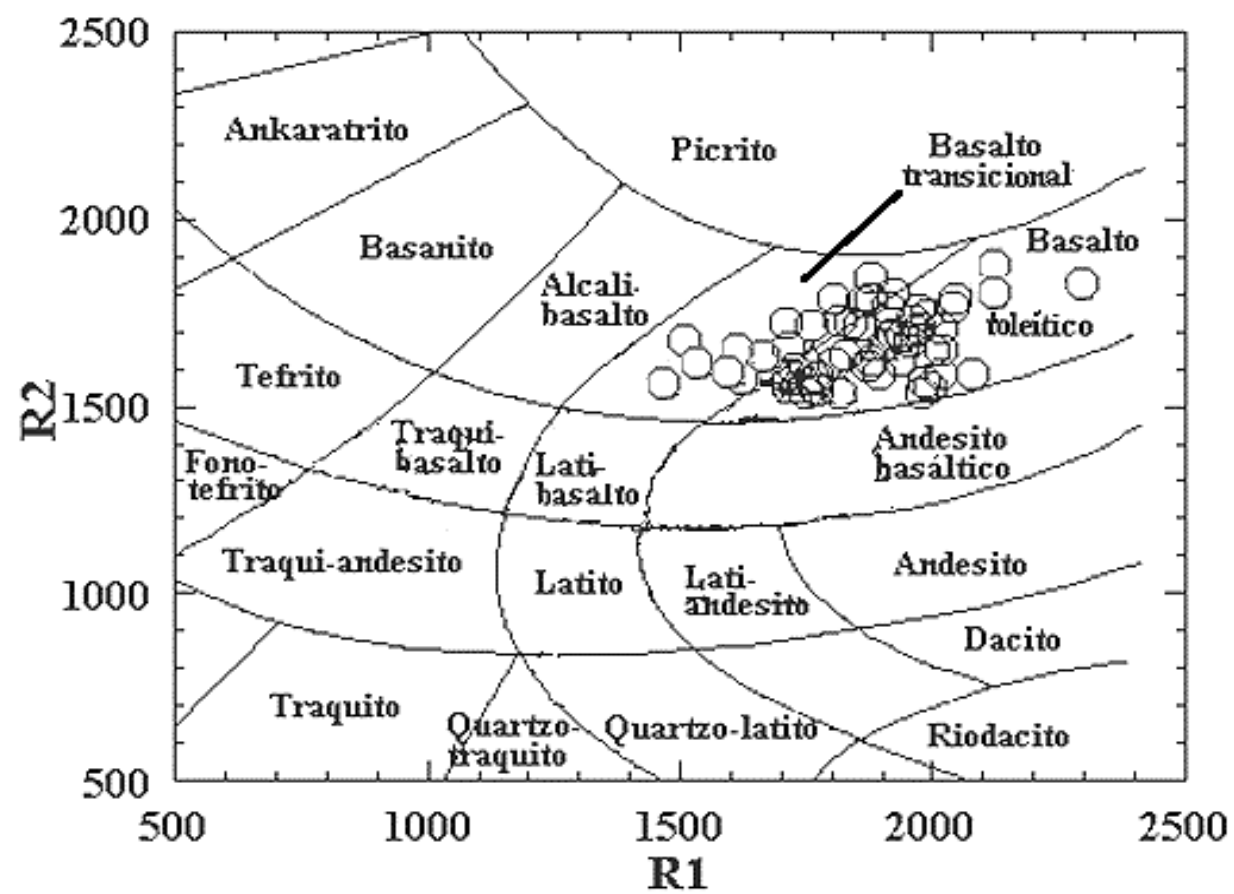

Figura 11 - Diagrama R1 x R2 (De La Roche et al. 1980), no qual as composições dos anfibolitos do setor sul do Cráton do São Francisco são projetadas nos campos dos basaltos toleiticos e transicionais. 

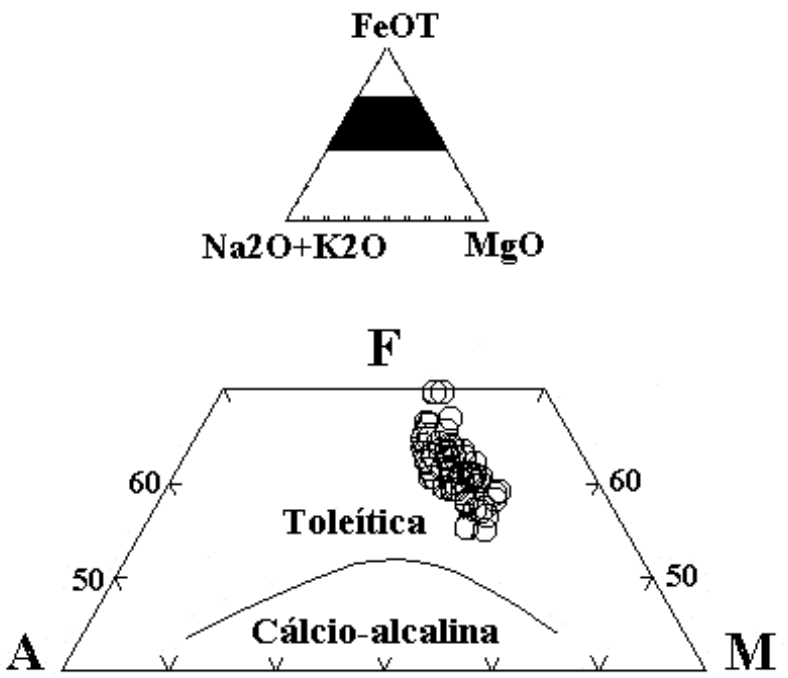

Figura 12 - Diagrama $\mathrm{AFM}\left(\mathrm{A}=\mathrm{Na} \mathrm{O}_{2}+\mathrm{K}_{2} \mathrm{O}, \mathrm{F}=\mathrm{FeO}\right.$ e $M=M g O$, Irvine \& Baragar 1971) com o lançamento das composições dos diques de anfibolito. A linha contínua faz a separação das séries magmáticas toleitica (acima) e cálcio-alcalina (abaixo).

consequentemente, o momento em que as ZCT estavam ativas. A baixa razão inicial ${ }^{87} \mathrm{Sr} /{ }^{86} \mathrm{Sr}(0,702)$ é reflexo da baixa razão $\mathrm{Rb} / \mathrm{Sr}$ da fonte mantélica dos diques.
DISCUSSÕES E CONCLUSÕES O evento compressivo transamazônico, de sentido aproximado SE para NW, assinalado por Alkmim \& Marshak (1998) no Quadrilátero Ferrífero, é aqui entendido como o responsável pelo surgimento das ZCT, conforme mostra a figura 19. Essas ZCT teriam se formado em condições reológicas de crosta intermediária, em virtude do seu caráter de tendência dúctil observado no campo. De acordo com a figura 19, é percebido que as ZCT predominantes, de movimentação sinistral, e as ZCT subordinadas, de movimentação dextral, ambas apontadas por slikensides e steps nos espelhos de falha, formam pares conjugados e simétricos em relação ao stress compressivo máximo horizontal $\left(\sigma_{1}\right)$. A partir das semelhanças entre as direções das ZCT e dos diques de anfibolito, é plausível inferir que o magma que lhes deu origem intrudiu sintectonicamente nas porções transtensionais das ZCT e, após a sua consolidação, foram metamorfisados em função da continuidade dos movimentos horizontais ao longo das $\mathrm{ZCT}$, tendo esta movimentação originado as "sheared margins" nos diques.

Este metamorfismo de caráter dinâmico, sofrido pelos diques máficos em condições de crosta já quase dúctil, foi o responsável pela recristalização generalizada da mineralogia original e pela ocorrência de reações metamórficas. Dentre estas reações, a mais expressiva é a da formação de hornblenda, com o auxílio de fluidos

Tabela 3 - Dados analíticos Rb-Sr para um dique Paraopeba, obtidos no Centro de Pesquisas Geocronológicas (CPGeo/USP).

\begin{tabular}{lcccccc}
\hline Material/número CPGeo & $\mathrm{Rb}(\mathrm{ppm})$ & $\mathrm{Sr}(\mathrm{ppm})$ & $87 \mathrm{Rb} / 86 \mathrm{Sr}$ & Erro & $87 \mathrm{Sr} / 86 \mathrm{Sr}$ & Erro \\
\hline Rocha total/13800 & 5,74 & 151,99 & 0,1093 & 0,0010 & 0,705400 & 0,000080 \\
\hline Máficos+Félsicos/13899 & 4,98 & 193,94 & 0,0742 & 0,0006 & 0,704391 & 0,000013 \\
\hline Máficos/13898 & 3,26 & 240,71 & 0,0391 & 0,0003 & 0,703256 & 0,000010 \\
\hline Félsicos/13897 & 3,62 & 23,93 & 0,4387 & 0,0036 & 0,715835 & 0,000097 \\
\hline
\end{tabular}

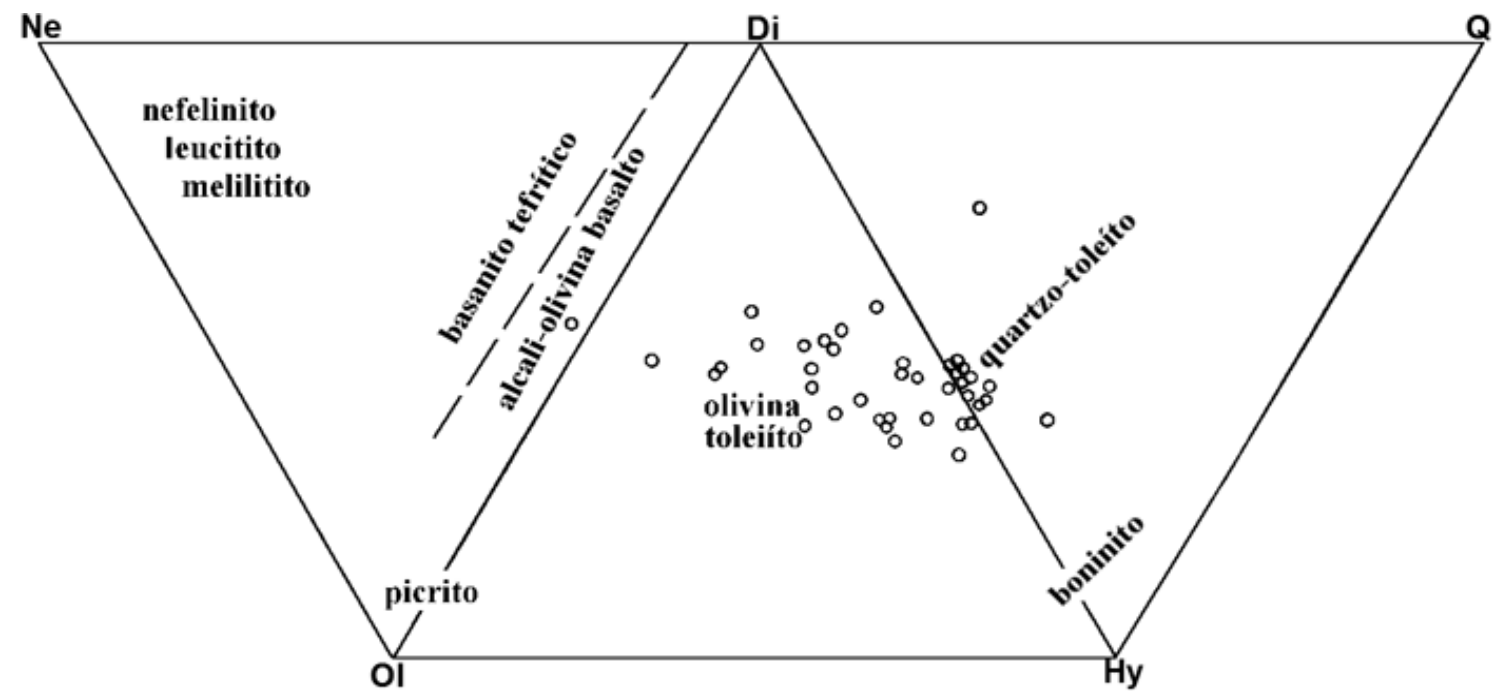

Figura 13 - Diagrama normativo CIPW (Ne-Ol-Di, Ol-Di-Hy, Di-Hy-Q) de Thompson (1984) para os anfibolitos estudados. 

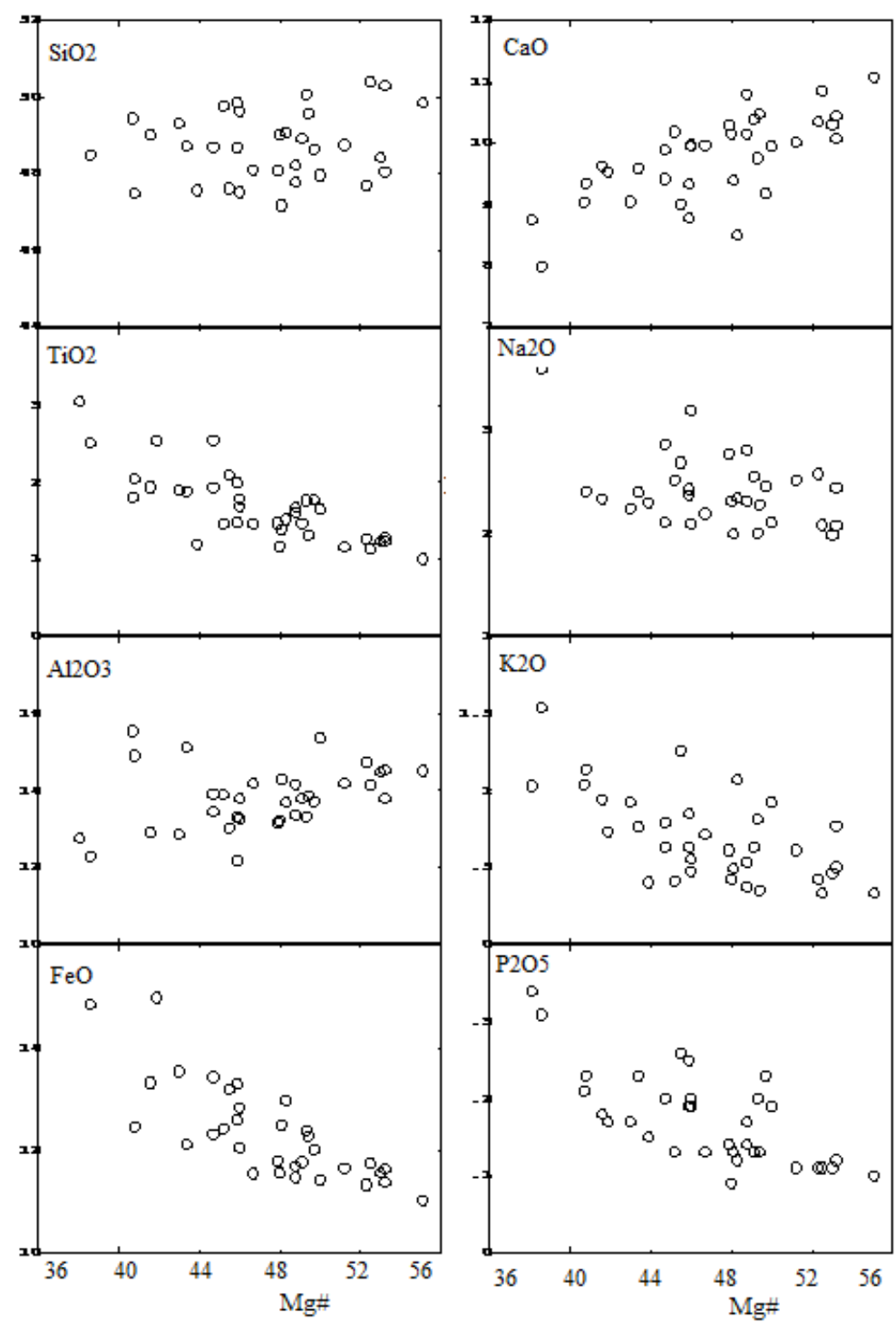

Figura 14 - Diagramas de variação de óxidos de elementos maiores em função do $\mathrm{Mg} \#$.

hidrotermais, a apartir da augita. Nesta reação, há o envolvimento do plagioclásio como reagente e granada almandina aparece como subproduto. Tal granada ocorre, muitas vezes, na forma de coronas, evidenciando condições de pressão intermediária a alta. Esta reação, abaixo escrita, caracteriza a fácies anfibolito alto (Winkler 1976): aumento de pressão

$$
\begin{gathered}
\text { augita }+\begin{array}{c}
\text { (plagioclásio) }+\mathrm{H}_{2} \mathrm{O} \rightarrow \text { hornblenda } \\
+/ \text { - granada almandina }
\end{array} \\
\text { metamorfismo progressivo }
\end{gathered}
$$

Segundo Yardley (1989), “o desenvolvimento de texturas coroníticas implica na transição direta de uma associação ígnea inalterada para uma associação típica de metamorfismo de alta temperatura e, usualmente, de alta pressão, sem um estágio interveniente de metamorfismo de grau mais baixo". Esta afirmação parece refletir, de fato, o acontecido a estes diques de anfibolito.

Como a presença de fluidos, principalmente água, é fundamental também para a ocorrência de transformações metamórficas em temperaturas decrescentes de metamorfismo, no que diz respeito às rochas máficas (Winkler 1976), os mesmos foram responsáveis pela formação de sericita, epidoto e carbonato a partir do plagioclásio, bem como pela formação de alguma tremolita-actinolita em certos diques às custas de augita primária remanescente. Estas reações, portanto, tiveram lugar já num metamorfismo regressivo posterior, sob fácies xisto-verde:

$$
\begin{gathered}
\text { plagioclásio }+ \text { fluidos }\left(\mathrm{H}_{2} \mathrm{O}+\mathrm{CO}_{2}\right) \rightarrow \text { sericita } \\
+ \text { epidoto }+/ \text { - carbonato } \\
\text { metamorfismo regressivo } \\
\text { augita }+\mathrm{H}_{2} \mathrm{O} \rightarrow \text { tremolita-actinolita } \\
\text { metamorfismo regressivo }
\end{gathered}
$$

A uniformidade composicional observada nas amostras analisadas sugere que os anfibolitos estudados derivaram de uma mesma fonte que, por sua vez, sofreu um grau de fusão parcial compatível com a geração de magmas toleíticos. É provavel que os magmas 

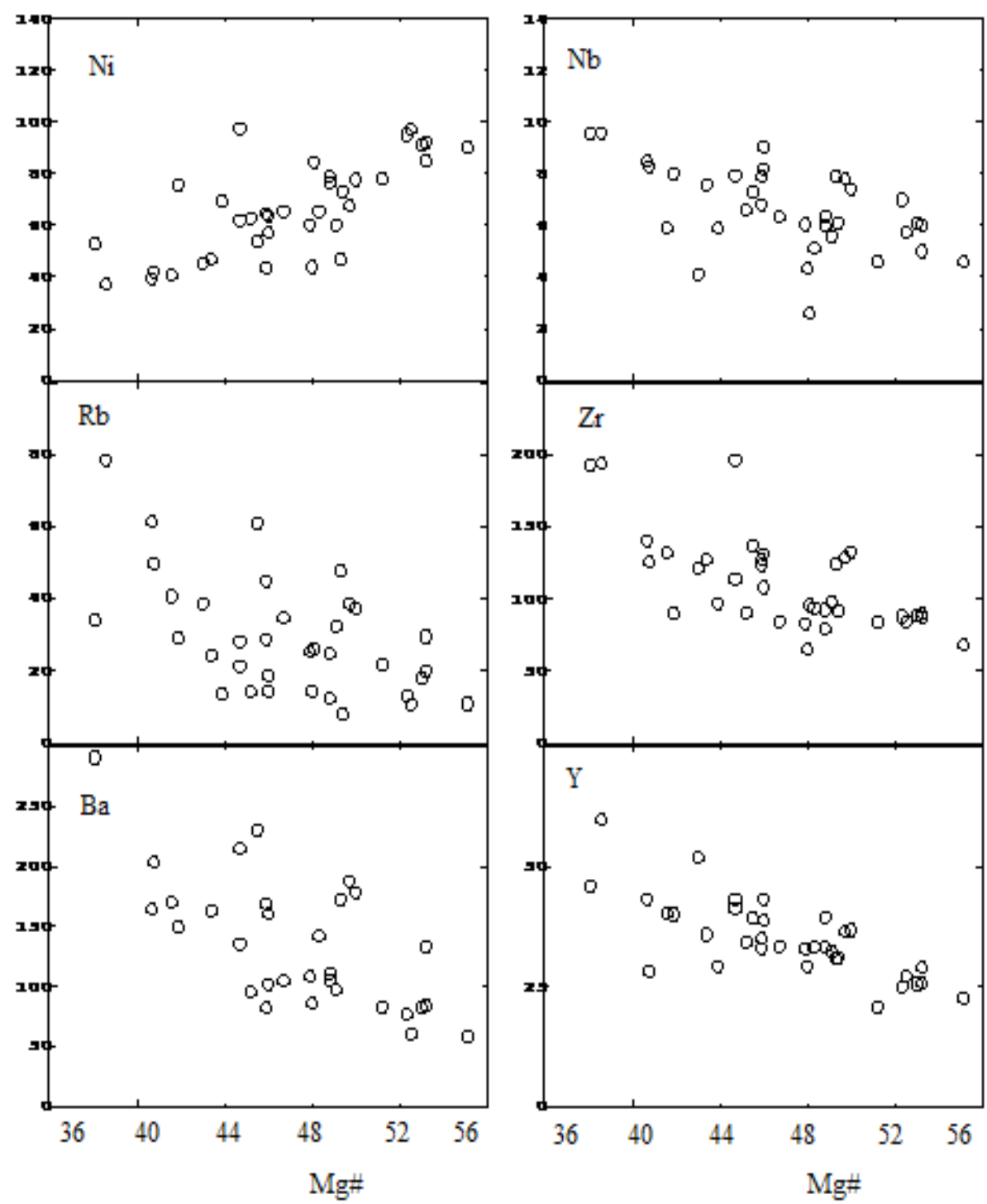

Figura 15 - Diagramas de variação de alguns elementos traços em função do $M g$ \#.

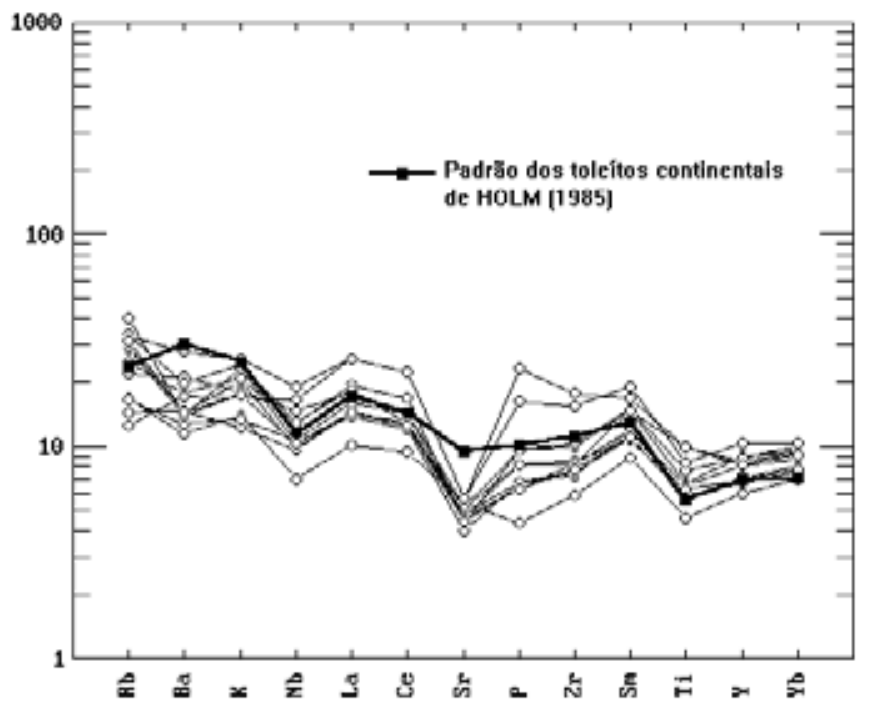

Figura 16 - Diagrama de variação de elementos incompativeis normalizados ao manto primordial (normalização segundo Wood et al. 1979) para alguns dos anfibolitos estudados.

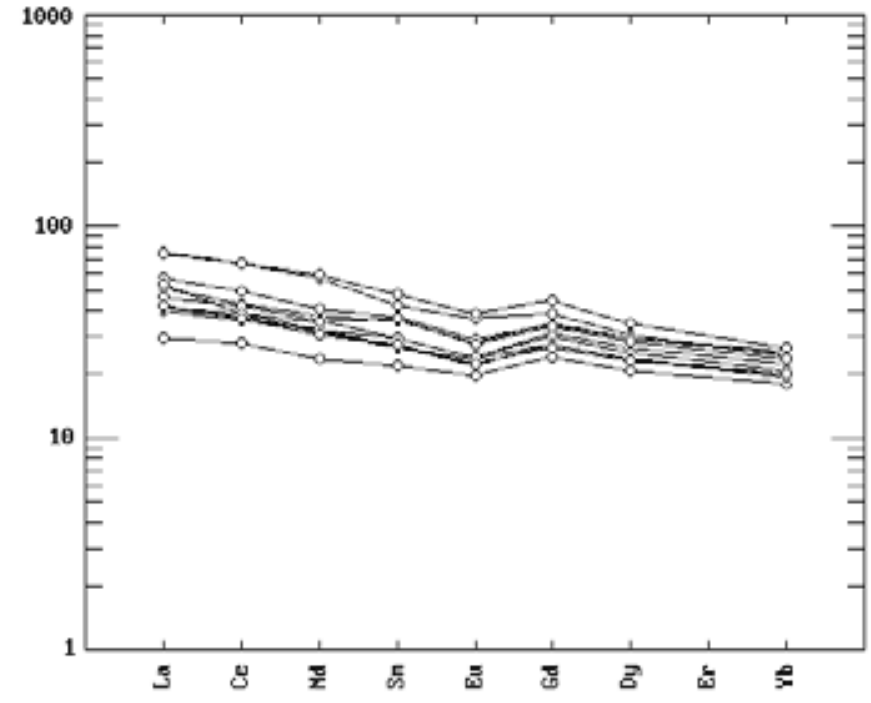

Figura 17 - Diagrama de variação de elementos terrasraras normalizados ao condrito (normalização segundo Evensen et al. 1978) para alguns dos anfibolitos estudados. 


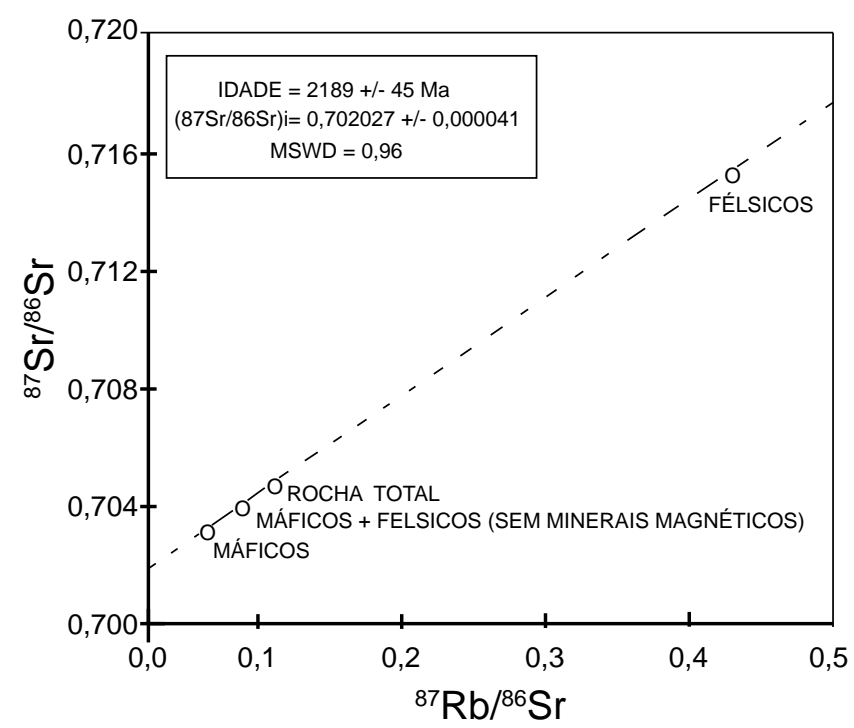

Figura 18 - Isócrona interna $\mathrm{Rb}-\mathrm{Sr}$ para um anfibolito do enxame Paraopeba.

precursores detas rochas tenham sofrido contaminação crustal durante seu posicionamento, ou mesmo durante o metamorfismo, o que é sugerido pela anomalia negativa de $\mathrm{Nb}$, característica do envolvimento de crosta continental, em destaque no diagrama da figura 16.

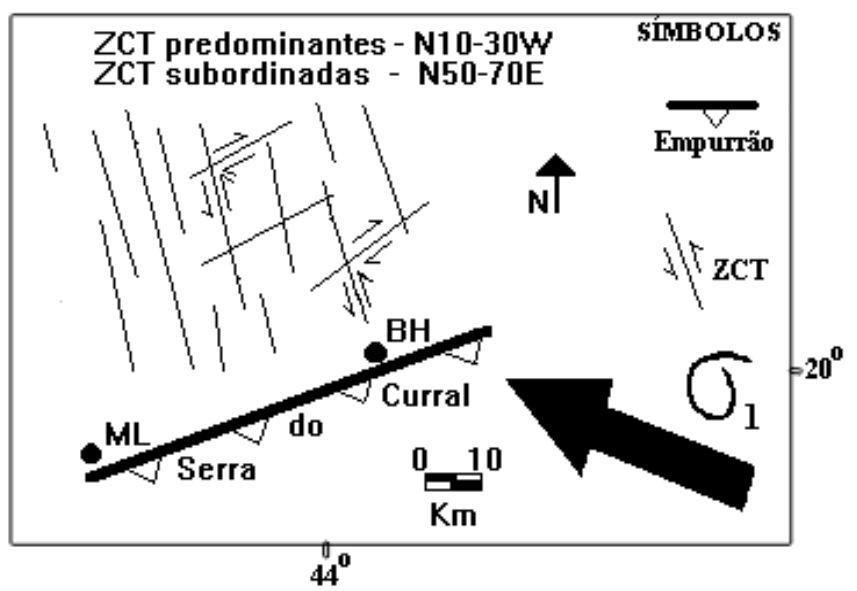

Figura 19 - Modelo de formação dos pares conjugados das ZCT dúcteis, a partir dos modelos regionais de stress. BH-Belo Horizonte, ML - Mateus Leme.
Alguns rochas originalmente porfiríticas podem ter a formação dos seus antigos fenocristais (hoje megacristais rotacionados pelo cisalhamento) explicada por uma etapa de residência crustal do magma em câmaras magmáticas antes da intrusão ou ao longo das porções transtensionais das ZCT.

Em resumo, a porção sul do Cráton do São Francisco é formada por uma plataforma estabilizada a 2,6 $\mathrm{Ga}$, constituída por gnaisses migmatizados, greensto$n e$ belts e plútons de granitoides. Durante a Orogenia Transamazônica (2,2-2,0 Ga), um cinturão colisional em forma de arco, denominado de Cinturão Mineiro (Teixeira et al. 2000), desenvolveu-se nas margens desta plataforma arqueana, formando plútons de granitoides e depósitos do tipo flysh (Fig. 2). O cinturão de cavalgamento/dobramentos foi criado em resposta a uma contração com vergência para NW, relacionada com a acresção de um arco de ilha e/ou terrenos exóticos nas margens leste e sudeste do Cráton do São Francisco. Neste evento, pode ter ocorrido o consumo de crosta oceânica e geração de tonalitos de origem mantélica e trondhjemitos $(2,162-2,124 \mathrm{Ga})$, seguidos por intrusões de granitos crustais sin a pós-colisionais (Teixeira et al. 2000). O Grupo Sabará, pertencente ao Supergrupo Minas, discutido no item da Geologia Regional, foi formado por volta de 2,1 Ga, em uma bacia de antepaís relacionada ao Cinturão Mineiro, com proveniência de sedimentos a partir da erosão dos depósitos arqueanos e paleoproterozoicos do Cinturão (Reis et al. 2002). Praticamente ao mesmo tempo, porém em níveis crustais mesozonais, os diques de anfibolito $(2,19 \mathrm{Ga})$ aqui investigados intrudiram em resposta à referida contração para NW, episódio durante o qual o magma máfico toleítico se alojou, cristalizou e se metamorfisou sintectonicamente ao longo das ZCT que se desenvolviam no Cráton São Francisco meridional.

A interpretação exposta neste artigo, sobre a intrusão e metamorfismo sintectônicos dos diques Paraopeba nas ZCT, está de acordo com o modelo de Cadman et al. (1990) apresentado na Introdução deste artigo.

Agradecimentos Ao CNPq pelo apoio financeiro, aos Drs. José Marques Correia Neves, José Moacyr Vianna Coutinho, Essaid Bilal e aos colegas do CPGeo e CPMTC que contribuíram para a construção deste trabalho.

\section{Referências}

Alkmim F.F. \& Marwhak S. 1998. Transamazonian orogeny in the Southern São Francisco Craton region, Minas Gerais, Brazil: evidence for Paleoproterozoic collision and collapse in the Quadrilátero Ferrífero. Prec. Research, 90:29-58.

Almeida F.F.M. 1977. O Cráton do São Francisco. Rev. Bras. Geoc., 7:349-367.

Babinski M., Chemale Jr. F., Schumus W.R. 1995. The $\mathrm{Pb} / \mathrm{Pb}$ age of the Minas Supergroup carbonate rocks, Quadrilátero Ferrífero. Brazil. Prec. Research, 72:235245.
Beswick A.E. 1982. Some geochemical aspects of alteration and genetic relations in komatiitic suites. In: Arndt \& Nesbitt (eds.) Komatiites. London, George Allen and Unwin, p. 283-308.

Cadman A., Tarney J., Park R.G. 1990. Intrusion and crystallization features in proterozoic dyke swarms. In: Parker A.J., Rickwood P.C., Tucker D.H. (eds.) Mafic dykes and emplacement mechanisms. Rotterdam, A.A. Balkema, p. 13-24.

Chaves A.O. 1996. Enxames de diques máficos proterozóicos da porção meridional do Cráton do São Francisco 
(M.G., Brasil). Dissertação de Mestrado, Instituto de Geociências, Universidade Federal de Minas Gerais, Belo Horizonte, 102 p.

Chaves A.O. \& Neves J.M.C. 2005. Radiometric ages, aeromagnetic expression, and general geology of mafic dykes from southeastern Brazil and implications for African-South American correlations. J. South Amer. Earth Sci., 19:387-397.

Cox K.G., Bell J.D., Pankhurst R.J. 1979. The interpretation of igneous rocks. London, Allen \& Unwin, 450 p.

De La Roche H., Leterrier P., Grandclaude P., Marchal M. 1980. A classification of volcanic and plutonic rocks using R1-R2 diagram and major elements analysis. Chem. Geol., 28:183-210.

Dorr J.V.N. 1969. Physiographic, stratigraphic and structural development of the Quadrilatero Ferrifero, Minas Gerais, Brazil. Washington, Geological Survey Professional Paper 641-A, 110 p.

Escher A., Escher J., Watterson J. 1975. The reorientation of the Kangamiut dyke swarm, west Greenland. Canadian Jour. Earth Sci., 12:158-173.

Evensen N.H., Hamilton P.J., Onions R.K. 1978. Rare earth abundances in chondritic meteorites. Geoch. Cosmoch. Acta, 42:1199-1212.

Holm P.E. 1985. The geochemical fingerprints of different tectonomagmatic environments using higromagmatophile element abundances of tholeiitic basalts and basaltic andesites. Chem. Geology, 51:303-323.

Irvine T.N. \& Baragar W.R.A. 1971. A guide to the chemical classification of the common volcanic rocks. Can. J. Earth Sci., 8:523-548.

Juliani C. \& McReath I. 1992. Petroquímica de metabasitos: metodologia para identificação de alterações magmáticas e pós-magmáticas. São Paulo, Geologia, Ciência e Técnica, 10:50-96.

Ludwig K.R. 2003. Isoplot/Ex 3.00: a geochronological toolkit for Microsoft Excel. Berkeley, Geochronology Center Special Publication, 70 p.

Machado N. \& Noce C.M. 1993. A evolução do Setor Sul do Cráton São Francisco entre 3,12 e 0,5 Ga, baseada em Geogronologia U-Pb. In: SBG-BA/SE, Simpósio sobre o Cráton do São Francisco, 2, Anais, p. 100-102.

Machado N., Schrank A., Noce C.M., Galthier G. 1996. Ages of detrital zircon fron Archean-Paleoproterozoic sequences: Implications for Greenstone Belt setting and evolution of a Transamazonian foreland basin in Quadrilátero Ferrífero, southeast Brazil. Earth Planet. Sci. Lett., 141:259-276.

Pandey B.K., Gupta J.N., Sarma K.J, Sastry C.A. 1997. Sm$\mathrm{Nd}, \mathrm{Pb}-\mathrm{Pb}$ and $\mathrm{Rb}-\mathrm{Sr}$ geochronology and petrogenesis of the mafic dyke swarm of Mahbubnagar, South India: implications for Paleoproterozoic crustal evolution of the Eastern Dharwar Craton. Precambrian Res., 84:181196.

Park R.G. \& Tarney J. (eds.). 1987. Evolution of the Lewisian Complex and comparable precambrian high grade terrains. London, Geol. Soc. Special Public., 315 p.

Pearce T.H. 1968. A contribution to the theory of variation diagrams. Contrib. Mineral. Petrol., 19:142-157.

Peloggia A.U.G \& Figueiredo M.C.H. 1991. Utilização de diagrama ferro-titânio na distinção química entre ortoe para-anfibolitos. Boletim IG-USP - Série Cientifica, 22:51-60.

Reis L.A., Martins-Neto M.A., Gomes N.S., Endo I., Jordt-Evangelista H. 2002. A bacia de antepaís paleoproterozóica Sabará, Quadrilátero Ferrífero, Minas Gerais. Rev. Bras. Geociências, 32(1):27-42.

Steiger R.H. \& Jager E. 1977. Subcomission on Geochronology: Convention on the use of decay constants in geochronology and cosmochronology. Earth Planet. Sci. Lett., 36:359-362.

Teixeira W., Sabate P., Barbosa J., Noce C.M., Carneiro M.A. 2000. Archean and Paleoproterozoic Tectonic Evolution of the São Francisco Craton, Brazil. In: Cordani U.G., Milani E.J., Thomaz Filho A., Campos D.A. (eds.) Tectonic Evolution of South America. Rio de Janeiro, FINEP, p. 101-137.

Thomaz Filho A., Kawashita K., Cordani U.G. 1998. A origem do Grupo Bambuí no contexto da evolução geotectônica e de idades radiométricas. Anais da Academia Brasileira de Ciências, 70:527-548.

Thompson R.N. 1984. Dispatches from the basalt front. 1. Experiments. Proc. Geol. Ass., 95:249-262.

Wilson B.C., Dixon J.M., Helmstaedt H. 1985. Dyke intrusion in shear fractures: Stress orientation and depht of emplacement. In: International Conference on Mafic Dyke Swarms, 1, Abstracts, p. 186-188.

Winchester J.A. \& Floyd P.A. 1976. Geochemical magma type discrimination: application to altered and metamorphosed basic igneous rocks. Earth and Plan. Sci. Let., 228:459-469.

Winkler H.G.F. 1976. Petrogenesis of Metamorphic Rocks. 4.ed. Nova York, Springer-Verlag, $334 \mathrm{p}$.

Wood D.A., Joron J.L., Treuil M. 1979. A re-appraisal of the use of trace elements to classify and discriminate between magma series erupted in different tectonic settings. Earth Plan. Sci. Letters, 45:326-336.

Yardley B.W.D. 1989. Introdução à Petrologia Metamórfica. Brasília, EDUnB, 340 p.

Manuscrito ID 19703

Submetido em 01 de fevereiro de 2011 Aceito em 27 de abril de 2011 